\title{
A Cultural Species and its Cognitive Phenotypes: Implications for Philosophy
}

\author{
Joseph Henrich ${ }^{1}$ - Damián E. Blasi ${ }^{1,2,3,4}$. Cameron M. Curtin ${ }^{1}$. \\ Helen Elizabeth Davis ${ }^{1} \cdot$ Ze Hong $^{1} \cdot$ Daniel Kelly $^{5} \cdot$ Ivan Kroupin $^{1}$
}

Accepted: 28 December 2021

(c) The Author(s), under exclusive licence to Springer Nature B.V. 2022

\begin{abstract}
After introducing the new field of cultural evolution, we review a growing body of empirical evidence suggesting that culture shapes what people attend to, perceive and remember as well as how they think, feel and reason. Focusing on perception, spatial navigation, mentalizing, thinking styles, reasoning (epistemic norms) and language, we discuss not only important variation in these domains, but emphasize that most researchers (including philosophers) and research participants are psychologically peculiar within a global and historical context. This rising tide of evidence recommends caution in relying on one's intuitions or even in generalizing from reliable psychological findings to the species, Homo sapiens. Our evolutionary approach suggests that humans have evolved a suite of reliably developing cognitive abilities that adapt our minds, information-processing abilities and emotions ontogenetically to the diverse culturally-constructed worlds we confront.
\end{abstract}

How much does culture shape people's brains and cognition? Does culture shape 'core' or 'basic' aspects of our attention, perception, thought, memory, reasoning, motivations, mentalizing abilities, decision heuristics/biases or moral intuitions? Does culture influence our epistemological inclinations such as what constitutes a good argument or solid evidence? Given that over $90 \%$ of all research in

Joseph Henrich

joseph.henrich@gmail.com

1 Department of Human Evolutionary Biology, Laboratory for Culture, Cognition and Coevolution, Harvard University, 11 Divinity Road, Cambridge, MA 02138, USA

2 Department of Linguistic and Cultural Evolution, Max Planck Institute for the Science of Human History, Kahlaische Str. 10, Jena 07745, Germany

3 Linguistic Convergence Laboratory, HSE University, Myasnitskaya Ulitsa, 20, Moscow 101000, Russia

4 Human Relations Area Files, 755 Prospect Street, New Haven, CT 06511-1225, USA

5 Department of Philosophy, Purdue University, 100 N. University St., West Lafayette, IN 47907-2098, USA 
the experimental social sciences is done with samples drawn from societies that are Western, Educated, Industrialized, Rich and Democratic (WEIRD), how appropriate is the pervasive, though often implicit, assumption that such findings can be generalized to the species (Henrich et al. 2010)? In this paper, we'll address these questions by reviewing the available research in psychology, cognitive science, cultural evolution, economics and allied fields. However, to properly understand how and why culture can shape our minds so profoundly, we begin with a brief introduction to the interdisciplinary field of cultural evolution.

\section{A Cultural Species}

Unlike other animals, humans have evolved genetically to rely heavily on acquiring a vast body of tools, techniques, heuristics, biases, motivations, emotions and knowhow from other members of our social groups (Boyd 2017; Henrich 2016; Laland 2017). To survive, even as hunter-gatherers living in the kinds of environments in which we genetically evolved, our species depend on a broad body of accumulated cultural know-how to find food, make shelters and care for infants. Our reliance on the products of this cumulative learning process-like fire, cooking, cutting tools and ecological knowledge-extends well back into our evolutionary history, at least hundreds of thousands of years, but probably over a million years. Over this period, our brains, along with their capacity to acquire, store, organize and retransmit cultural information, expanded dramatically, driven by a spiraling accumulation of adaptive practices and technologies generated by cultural evolution (Muthukrishna et al. 2018a; Muthukrishna and Henrich 2016; Street et al. 2017).

To lay a foundation for understanding culture, researchers in the emerging field of cultural evolution begin by asking how natural selection might have shaped our genes to improve the effectiveness of our learning. For example, how might natural selection influence the who, what and when of cultural learning, to more effectively select the most adaptive aspects of other people's behavior, strategies, motivations, beliefs and heuristics (Laland 2004; Rendell et al. 2011). Testing predictions derived from this evolutionary approach to cultural transmission, a large body of evidence shows that learners rely on cues related to prestige, success, skill, ethnicity, sex and age when deciding 'who' to learn from (Chudek et al. 2013; Harris and Corriveau 2011), as well as cues that mark 'what' to learn and 'when' to use social learning over personal intuitions or direct experience (Barrett and Broesch 2012; Morgan and Laland 2012; Muthukrishna et al. 2016). Most important for our purposes here, laboratory studies have already shown how adults, children and often even infants culturally acquire a number of different aspects of their psychology, including decision-making heuristics (Rosenthal and Zimmerman 1978), fairness preferences (Blake et al. 2016; Salali et al. 2015), altruistic preferences (Rushton 1975), perceptual biases (e.g., overconfidence (Cheng et al. 2020)), goals (Hamlin et al. 2008, 2009) and food tastes (Birch 1987). It's well established that many features of reasoning, motivation, affect, judgment and decision-making can be culturally transmitted (Bandura 1977; Henrich 2020). 
This work has provided both the theoretical and empirical micro-foundations for building mathematical models of cultural evolution and culture-gene coevolution. These models, by aggregating the impacts of individual-level learning processes across a population, provide a bottom-up approach to explaining sociological phenomena like large-scale cooperation (Boyd et al. 2010, 2011; Henrich and Henrich 2007), social norms (Chudek and Henrich 2010), social stratification (Henrich and Boyd 2008), ethnic groups (McElreath et al. 2003), cultures of honor (McElreath 2003), status (Henrich et al. 2015; Henrich and Gil-White 2001), divination (Hong and Henrich forthcoming), shamanism (Singh 2018a), witchcraft (Singh 2018b), and innovation (Henrich 2004, 2009; Muthukrishna and Henrich 2016). Culture, by this account, represents information stored in people's heads that got there via cultural learning or direct experience induced by various cultural products, like norms, technologies, languages or institutions.

Perhaps most important for our discussion here, researchers in this field argue that our large brains, which evolved genetically in a world shaped by norms, institutions, technologies and languages, embody an information-processing plasticity that permits them to adapt ontogenetically and over cultural evolutionary time to the affordances, constraints and incentives created by the culturally-constructed worlds we have long inhabited. That is, we have evolved genetically to have a degree of developmental plasticity (Henrich 2016; Herculano-Houzel 2019; Laland 2017). This cognitive and neurological flexibility, including our late myelinization, is a genetic adaptation to confronting a culturally-constructed world (Gómez-Robles et al. 2015; Miller et al. 2012; Sherwood et al. 2012; Sherwood and Gómez-Robles 2017). We've evolved to be self-programmable to a degree not found in other species.

This evolutionary approach to humans has implications that may be of interest to philosophers:

1. It dissolves the epistemologically troubling 'nature versus nurture' dichotomy, which has often pitted 'evolutionary' or 'biological' explanations against those based on 'culture' or 'learning'. By approaching our capacities for learning as adaptations, which are ultimately traceable to the operation of natural selection, it seats all explanations within an evolutionary framework. Within this framework, explanations will vary in their downstream (more proximate) mechanisms. 'Cultural explanations' are then simply those that specify a substantial role for social learning in a causal chain that accounts for particular phenotypic distributions.

2. From this perspective, culture is part of our biology in two distinct ways: First, many aspects of our genetically evolved physiology, anatomy and cognition have been shaped by selective forces traceable to cultural evolution. As the examples below will make clear, one cannot study either human physiology or our cognitive architecture without considering culture-driven genetic evolution. Second, culture shapes our biology-including our brains and anatomy-through non-genetic inheritance processes-so, even putting aside culture-gene coevolution, aspects of our biology evolve culturally. This means that our brains and psychology have been evolving culturally over historical time (Muthukrishna et al. 2021). 
3. Cultural evolutions stands alongside natural selection acting on genes as a nonconscious and unintentional process capable of generating adaptive or functional complexity (Henrich 2016).

Unfortunately, dualistic assumptions about minds versus bodies/brains and nature versus nurture/learning still pervade much thinking in many parts of the social sciences and humanities. To address this, we begin our review by looking at how culture shapes (non-genetically) human bodies, literally from head to toe. As you'll see, culture alters our anatomy and physiology, leading medical researchers focused on WEIRD people to make incorrect inferences about basic aspects of human psychology, health, aging and disease. If culture can alter our physiology and anatomy, do we really believe it will leave our reasoning and judgment unaffected? Next, we focus on how culture influences people's sensory abilities, perceptions, spatial cognition and mentalizing. Each of these represents a fundamental feature of our species that has long been crucial to our survival. Yet, key aspects in these domains vary across populations in important ways. Down shifting into the domain of greater interest to philosophers, we review the research on thinking styles, reasoning, epistemic norms and judgement. Here, we show that not only do these vary among populations, but that WEIRD participants anchor the extreme ends of global distributions. We close our empirical review with some concerns about scholars' overreliance on intuitions and insights rooted in the use of English. English is peculiar along many important dimensions and may be quite unrepresentative of most spoken languages over human history.

\section{Culture Shapes Humans in Profound Ways}

Scholars often have the intuition that culture can only shape superficial aspects of our minds; or worse, they persist in applying an outdated digital computer metaphor that incorrectly partitions brains and minds into 'hardware,' supposedly studied by neuroscientists and psychologists, and 'software,' allegedly studied by anthropologists and sociologists. This ill-fit metaphor leads them to infer there's some hermetically sealed set of cognitive hardware that can't be influenced by culture.

Our first step in addressing such misconceptions is to illustrate how culture shapes features of human anatomy and physiology, including features that have clearly been the target of natural selection-i.e., our genetic adaptations. We'll further show how medical researchers, physiologists and anatomists have made errors in understanding our species' bodies as a consequence of their readiness to generalize from studies of people from societies that are Western, Educated, Industrialized, Rich and Democratic (WEIRD) to Homo sapiens. Reliance on these peculiar populations, who grow up in environments without evolutionary precedence, have led to confusions regarding the nature of "human" body temperature, running form, hormonal life cycles (e.g., testosterone), foot mechanics, and the functioning of our immune systems. Overly enthusiastic generalizations from WEIRD samples have led medical researchers to incorrectly assume that many chronic diseases were the result of aging rather than a specific response to life in particular environments. 
Let's start at the bottom. When paleoanthropologists first started to compare the fossilized feet and footprints of Australopithecines to "modern" humans they declared that the Australopiths had "primitive feet," noting for example their high arches. However, decades later, it turned out that the unusual features of Australopith feet could be found in contemporary human populations once researchers stopped focusing on people who grew up wearing hard soled shoes (Tuttle et al. 1990, 1991). Compared to most societies that have ever existed, habitually-shod populations, especially those who don snug-fitting, hard soled shoes, have unusual feet, including fallen arches. WEIRD people even put shoes on their children!

Is the foot a peculiar exception? Well, when researchers began to study 'the human running form,' they also got the wrong answer. The reason is that they studied runners who had adapted their form to wearing cushioned running shoes-essentially strapping pillows to their feet. Equipped with such cushions, runners tend to land on their heels. By contrast, populations who habitually run barefoot, or in any sort of minimalist footwear, develop a running style in which they land on their mid- or forefoot. Analyses of the biomechanics of habitually barefoot runners suggest that humans evolved genetically to run long-distances, and specifically to absorb shocks via a mid or fore-foot strike (where the calf muscle acts as a shock absorber), not a heel strike. Studying runners who grew up in a world with cushioned running shoes (1975 to 2020?) suggested that people didn't evolve to run because the magnitude of the pounding created by chronic heel strikes leads to knee problems, plantar fasciitis and other issues (Bramble and Lieberman 2004; Lieberman 2012). Of course, recognizing the potential role played by running shoes is relatively easy compared to recognizing all of the more subtle norms, technologies and aspects of language that shape our thinking, feeling and intuitions in a manner analogous to how sneakers distorted our running form.

Culture also shapes our hormones-specifically, how men's testosterone (T) changes over the life course. Like many bird species (and lizards), testosterone levels in males rise during mate-seeking, mating and status competition, but then decline after monogamous pair-bonding and when caring for offspring (Hooven 2021). Laboratory evidence has linked testosterone to status seeking and zero-sum thinking, which often results in impatience, risk-taking, mistrust and reduced responsiveness to learning from pain. The difference between birds and humans is—of coursethat human mating and pair-bonding is heavily regulated by norms and institutions, like marriage. Societies vary in their marriage institutions, but from a global and historical perspective, modern monogamous marriage is quite peculiar. Most societies have permitted high status men to marry polygynously, and often placed few or no constraints on their sexual behavior. The available evidence suggests that men's relative testosterone levels over their life course depends on the marriage and childcare norms they confront. In normatively monogamous societies, where fathers are expected to provide some childcare, men's T-levels drop when they marry and again when their first child arrives. This decline often continues as they age, sometimes resulting in chronically "low-T", a recognized clinical condition. By contrast, there's little indication that men's T-levels drop after marriage in polygynous societies (after 
all, they remain on the marriage and mating market) or after children arrive (since norms in such societies rarely encourage fatherly infant care). Moreover, any agerelated declines in men's relative T-levels are mild compared to the more dramatic drops common in WEIRD societies. Once again, the medical establishment erred in thinking that the large T-level declines they observed in WEIRD men were the inevitable products of aging (Henrich 2020; Henrich et al. 2012). It turns out, there's an interaction between aging and marriage norms that one entirely misses by studying WEIRD people, with their historically peculiar marriage system and consequent cultural endocrinology.

What's the internal temperature of the human body? In 1851, the German physician Carl Reinhold Wunderlich measured the temperature of 25,000 patients and set the modern standard for body temperature at $37^{\circ} \mathrm{C}$ or $98.6^{\circ} \mathrm{F}$. But, is this measurement a feature of human bodies?

Surprisingly, no. It turns out that mean body temperature in the U.S. has been declining by roughly 0.3 degrees per decade since the mid-nineteenth century (Protsiv et al. 2020). Similarly, among the Tsimane, who rely on slash-and-burn agriculture and hunting for their subsistence in the Bolivian rainforest, mean body temperature has been declining by 0.5 degrees per decade since 2000 . Why?

The answer remains a bit of a mystery, but part of the decline is likely due to a reduction in both physical exercise and parasite loads, which most humans have routinely carried until very recently (Yegian et. al. 2021; Gurven et al. 2020). If you study WEIRD people, you even get "human" body temperature wrong. Our body temperature depends, at least in part, on the demands of our economic lives and epidemiological contexts. Clean water, antibiotics, inactivity, vaccinations and other unidentified factors have left us with low body temperatures, uncharacteristic of those found over our species evolutionary history.

The recent and dramatic reductions in the parasite loads carried by many human populations - a pattern first appearing in WEIRD people-has misled researchers in another way. Medical science has long taken chronic inflammation to be a cause of heart disease. However, these links only appear in populations with very low parasite loads. That is, in populations with high parasite loads, chronic inflammation is not associated with heart disease (Gurven et al. 2009; Gurven et al. 2016; Gurven and Lieberman 2020). A leading explanation suggests that natural selection may have depended on the reliable presence of helminths, a type of parasite, in our bodies as a means to manage the negative impact of chronic inflammation. Once cumulative cultural evolution devised ways to eliminate helminths from our bodies, chronic inflammation became a new factor contributing to rising rates of heart disease. The lesson here is that studying people living in helminth-free environments led to an impaired understanding of the nature and evolution of heart disease.

Arriving at our heads, this epidemiological process may explain another pattern: the appearance of facial acne varies from $0 \%$ in some small-scale societies up to 95\% in urban WEIRD societies (Campbell and Strassmann 2016). Such data hint that acne was likely rare over much of our species evolutionary history and suggest that the science of acne that has developed by studying WEIRD people is missing 
some major risk factors-which are homogenous across WEIRD societies. Acne is cultural.

Natural selection has substantially shaped our bite and teeth relative to other primates (Lieberman 2011), so is this a reliably developing feature of our anatomy? Today, most contemporary humans display a particular bite configuration - the upper teeth are projected in front of the lower teeth during occlusion ('overbite') spanning a small acute angle in relation to them ('overjet'). This configuration was (and still is) deemed as the normal, healthy bite, emerging early in life and accompanying individuals throughout adulthood (Heikinheimo et al. 2012; Tibana et al. 2004). Many people today also need braces for an orderly smile (Lieberman 2013). However, researchers studying foraging populations have argued that the type of bite that has characterized most of our species' history has neither overbite nor overjet, and is instead defined by the full occlusion of the upper and lower teeth, creating an edge-to-edge bite (Begg 1954). This dental pattern likely arose from a developmental response to heavy wear diets, which progressively shaped the bite and the orofacial features of individuals from overbite and overjet in pre-adolescent individuals to an edge-to-edge bite in adults. This is the 'normal development' from an evolutionary perspective.

This seemingly unremarkable change in people's bite configuration had substantial consequences. First, the shift likely led to observable changes in the speech sounds present in the world's languages (Blasi et al. 2019), giving rise to labiodentals like ' $\mathrm{f}$ ' and ' $\mathrm{v}$ ' sounds. If you are a linguist, you can't get human phoneme variation correct without understanding how technology shapes the ontogeny of the human bite and how that influences the sounds found in languages. Second, the close alignment of teeth in this edge-to-edge configuration likely inhibited the emergence of cavities and other periodontal diseases compared to contemporary configurations (Kaifu et al. 2003). Chewing tough food and working materials like leather over childhood may also have encouraged the straighter and more uniform spread of teeth, thus avoiding the situation that prompts the use of braces today. Thus, by favoring softer foods and technologies capable of replacing the tasks once done with our teeth, cultural evolution first produced the jumbled smiles and dental problems found in many agricultural populations (Lieberman 2013). Now, cultural evolution is trying to fix the problem it created with braces and dentists. The 'human' bite has continued to evolve culturally over history as the task demands on our teeth and jaws have changed.

\subsection{Sensory Abilities and Perception}

It's a short step from the effects of culture on our anatomy and physiology to its impact on our senses and perceptions. Perhaps the oldest lines of research on this come from studying how culture influences myopia, effectively changing people's visual acuity. Among hunter-gatherer populations, who live in the kinds of environments that dominated most of our evolutionary history, myopia is almost non-existent (Cordain et al. 2002). In contrast, today in the industrialized world, nearly $25 \%$ of the population is myopic, and need glasses to correct their vision. Debates persist 
on the precise causes of this, but key influences include urban environments, time spent indoors and reading during childhood. So, if you study 'human' visual acuity by focusing on WEIRD people, you might infer that "it's genetic" (because genetic variation does contribute). However, this would be misleading since myopia is now thought to be entirely a gene-environment interaction-if you grow up as a forager, no genes make you more susceptible to myopia because the relevant cultural practices aren't found in these populations. These 'myopia genes' only matter at all in recent environments. Thus, studying WEIRD people means you get human visual acuity wrong and even your inferences about the role of genes could be misleading.

Similarly, a venerable line of research going back to 1901 by W.H.R. Rivers suggests that our susceptibility to various visual illusions also varies across societies (Berry 1968; Bremner et al. 2016; Jahoda 1966; Rivers 1901; Segall et al. 1963, 1966). This includes some of the most common illusions, such as the HorizontalVertical, Sander-parallelogram and the Ebbinghaus illusions as well as the famous Mueller-Lyer Illusion. This cross-cultural variation is consistent with older developmental data showing that our susceptibility to particular illusions often changes gradually over our lives (Henrich 2008) and more recent evidence suggesting that illusions are influenced by how our minds calibrate to the statistical patterns found in our visual environments as they convert the 2-D images projected onto our retinas to 3-D representations (Howe and Purves 2005).

Curiously, this well-established population-level variation has been ignored in philosophical debates: long after substantial evidence was available, the MuellerLyer Illusion was claimed to be a "cognitively impenetrable" creation of the human mind by Jerry Fodor in his debates about modularity with the Churchlands (McCauley and Henrich 2006). Yet, research done in the 1960s had already revealed substantial variation in the strength of the Mueller-Lyer illusion, with WEIRD people showing the greatest susceptibility and Kalahari hunter-gatherers not seeing the illusion at all. ${ }^{1}$

WEIRD intellectuals have long argued that olfaction is the least important of the five senses, and this has been the standard view in psychology and even in anthropology. Yet, this may be a WEIRD bias that we culturally inherited from our farming forebearers. Recent work among both forager-horticulturalists in Bolivia and hunter-gatherers in Malaysia suggests that these populations are superior at identifying scents and possess a richer vocabulary that includes an array of basic (abstract) scent terms (Majid and Kruspe 2018; Sorokowska et al. 2013). This is striking because some WEIRD intellectuals have suggested that it's impossible to speak abstractly about scents (Majid and Burenhult 2014), presumably because

\footnotetext{
1 While the evidence showing variation in the strength of these illusions across populations remains largely unchallenged, researchers working with nine newly-sighted children have argued that the default, pre-experience, visual calibration in humans generates some detectable susceptibility to the Mueller-Lyer and Ponzo illusions (Gandhi et al. 2015). This may well be the case, but our point is that the perception of, and associated strength of some illusions, varies across populations-not that all illusions are produced only by experience. Nevertheless, this study is beleaguered by relying on a tiny sample, reporting only a crude measure of illusion susceptibility, and failing to explore how long these nearly blind children were sighted earlier in their lives.
} 
their languages and cultural routines didn't habituate and automate the application of such concepts (more on this below). While philosophers have recognized some of this important work on olfaction (Barwich 2020), it's less clear that the field has fully digested the implications of relying on WEIRD neuroscience (Han et al. 2013; Kitayama et al. 2017, 2019).

\subsection{Spatial Navigation}

Going well back into our evolutionary history, humans have confronted the need to think about space in a variety of ways. Like other animals, human spatial navigation and memory present crucial cognitive challenges that have been linked to a variety of cognitive abilities, and human foragers have long needed to navigate through space and remember the details of their home ranges to avoid predation, find mates, and remember the location of objects or past events (Milton 1988; Powell and Mitchell 2012). Some of the most commonly studied spatial cognitive abilities include (1) spatial memory and navigation (which allows us to store and retrieve information about our surroundings, remember where objects are located, or where an event took place), (2) spatial perspective-taking (how objects in the environment are oriented in relation to another), and (3) mental rotation (the ability to imagine how an object that has been seen from one perspective would look if it were rotated in space or viewed from the new perspective). Decades of research have explored the degree to which these cognitive features are products of innately available representations (Wang and Spelke 2002), how basic spatial processes interact with the symbolic world (Stokes 2018), and what the role of individual differences is (Hegarty and Waller 2005; Proulx et al. 2016).

Though spatial reasoning and associated cognitive abilities, such as spatial memory and mentalizing, improve throughout children's development (Hart and Moore 1973; Vasilyeva and Lourenco 2012), there are substantial performance gaps within and across populations that remain largely unexplained. For example, in an investigation of navigational ability between two WEIRD populations in Padua, Italy and Salt Lake City, Utah, USA, Barhorst-Cates et al. (2021), found that adults in Padua, who have substantially lower pointing error within their own city when compared to Utahans, were no more accurate at pointing to familiar distant targets outside their cities $>10 \mathrm{~km}$ away than participants in Utah $\left(\sim 37^{\circ} \mathrm{error}\right)$.

Compare these WEIRD populations to traditional societies in Africa and Amazonia. In Amazonia, forager-horticulturalists-the Tsimane of Bolivia-were asked to point from their home village to distant communities over $60 \mathrm{~km}$ away that are only accessible by canoe via a sinuous Amazonian tributary. Here, Tsimane adults pointed with an average of just $20^{\circ}$ error (Davis et al. in press) and children ( $\mathrm{M}=11.00$ years old, $\mathrm{SD}=3.6$ years) averaged only $\sim 40^{\circ}$ error (Davis and Cashdan 2019). On the other side of the globe, in the arid regions of Nambia, Twa pastoralistforager children ( $\mathrm{M}=11.6$ years old, $\mathrm{SD}=3.4$ years) pointed to distant locations up to $90 \mathrm{~km}$ away with considerable accuracy, averaging only $\sim 20^{\circ}$ error (Davis et al. 2021), which is on par with adults in their communities and Tsimane adults, but is 
twice as accurate as the navigationally-challenged adults sampled in Padua and Salt Lake.

Though considerable prior work has aimed to identify and relate individual differences, surprisingly little work has focused on the characteristics of a navigator's home environment, as well as on the cultural and daily navigational demand of daily life, as an explanation for why individual differences may be observed. However, a few classic studies, along with a wide range of recent evidence from the Spatial Cognition and Navigation (SCAN) lab have demonstrated how local environments, economic requirements and particular ecologies, and social norms and cultural institutions shape human spatial cognitive abilities (Barhorst-Cates et al. 2021; Cashdan et al. 2016; Crittenden et al. 2021; Davis and Cashdan 2019). First, in the Padua and Salt Lake City study, Barhorst-Cates et al. (2021) found through interviews focused on daily activities and city mapping that the greatest influence on navigation strategies and accuracy between the two WEIRD populations was home environmental experiences. Padua adults, who live in a winding city filled with bridged moats and arcaded streets, were twice as accurate when pointing to within city targets when compared to Americans in Salt Lake City, who live on a metropolitan grid with few proximal cues but some distinct distal geological markers. The study further suggests that mode of travel and street network entropy may further improve or inhibit the development of navigational skills. This conclusion is further supported among the Tsimane and Twa. Among the Tsimane, labor demands require navigating dense tropical canopies with frequent cloud coverage that obscures distal cues. Though there are ecological risks, children are given considerable latitude to explore without adult supervision and are expected to contribute to household labor and food procurement activities from an early age (Stieglitz et al. 2013; Davis and Cashdan 2019). Relatedly, among the Twa, men and boys have historically traveled long distances to hunt, and in more recent decades to find grazing lands and water for their herds, while women foraged nearby for medicinal and edible plants.

Similar links between ecology, social norms, and navigational ability have been identified in other studies among non-WEIRD children. For example, among the Mbendjele BaYaka in the Republic of Congo, children spend considerable time in work and play away from home beginning at an early age (Lew-Levy et al. 2020), and on a similar pointing task their navigational error was found to be as low as $7^{\circ}$ (Jang et al. 2019). Likewise, in a seminal study among Alaskan school children (Kleinfeld 1971), children of native Alaskan descent, primarily Iñupiaq, demonstrated far greater visual spatial memory than their European-descent peers. Building on earlier findings from Berry (1966) among Nunavut Inuit women and men, Kleinfeld attributed the differences between the two populations to the freedom to explore granted to children in Inuit populations. While children from both the Tsimane of Bolivia and Twa of Namibia performed well on tasks of spatial memory and navigation, they also showed highly developed spatial perspective taking skills, with only around $66^{\circ}$ error when asked to imagine that they were in a known location far away and then navigate from that mentalized location to a third target location. Compared to the Tsimane and Twe, studies in WEIRD populations suggest lower overall performance on spatial perspective taking (Vander Heyden et al. 
2017), as well as large intra-population differences, which may in part be culturally influenced (Tarampi et al. 2016).

Given the role that ecology and socialization practices play on navigational and pointing ability, it is critical to reassess how some previously assumed genetic differences may be amplified by, or even the product of, social norms or cultural institutions. Sex differences have long been a focus of spatial cognitive research in WEIRD populations (Linn and Petersen 1985; Voyer et al. 1995). Many studies report that men (compared to women) learn spatial environments faster and can recall routes with fewer errors (Coluccia and Louse 2004; Galea and Kimura 1993). And, although there is still some debate about the age that differences in spatial abilities are first observed, most WEIRD studies suggest that sex differences emerge during middle childhood and early adolescence (Voyer et al. 1995). Given the consistency of these observed differences, evolutionary hypotheses have been proposed to explain why biological sex differences in spatial ability might exist (Geary 2010). These hypotheses focus on the benefits males gain from meeting various navigational challenges, including mate seeking (Gaulin et al. 1990; Geary 1995; Jones et al. 2003) or the emergence of the sexual division of labor in humans during the Pleistocene (Silverman et al. 2007).

Consistent with these arguments, it has been observed in both WEIRD societies (Hart 1979; Matthews 1987) and small-scale societies (Whiting and Edwards 1992) that children first demonstrate significant sex differences in range size during middle childhood, when they begin participating in sex specific tasks and start spending more time with same-sex peers. These differences are argued to increase after adolescence, when boys enter their mate seeking years (Miner et al. 2014). For example, Vashro and colleagues (Vashro et al. 2016; Vashro and Cashdan 2015) found that among Twa pastoralists the average daily range size for Twa men was greater than that of Twa women. They also demonstrated that men had (1) lower average error on a navigational pointing task compared to women and (2) greater accuracy on a mental rotation task. Supporting an evolutionary account, Twa men with larger ranges were also found to have fathered more children by more women-i.e., they had higher fitness.

However, sex differences in navigational cognition don't always emerge. In East Africa, sex differences in navigational abilities were not found among participants still living a traditional foraging lifestyle; instead, they only arose among participants from communities located closer to the market towns, where people tended to be less mobile and had smaller range sizes (Cashdan et al. 2012). Likewise, among Tsimane adults, where men and women both travel far for foraging activities, sex differences in navigational ability were not observed (Trumble et al. 2015). Instead, Tsimane's daily mobility, wayfinding/pointing error, and mental rotation were related to differences in age, participation in the wage labor market, and more years of formal education (Davis et al. in press). This raises questions about the role mobility patterns, market exposure, and formal schooling play in spatial cognitive development.

Illustrating the power of institutions to have unintended cognitive consequences, consider the impact of boarding schools for the Twa, where sex differences have been consistently observed among adult men and women (as mentioned above). When 
both boys and girls began traveling on foot weekly to government funded boarding schools, they demonstrated precocious navigational skills and no sex differences with increased mobility. Notably, boys and girls outperformed most adult women who had not had access to formal schooling growing up and whose mobility has been traditionally constrained by childcare and domestic work close to camp (Davis et al. 2021). In contrast, among tropical forager-horticulturalists, where mobility patterns vary by age but not gender, children who spent more time attending local village schools traveled less than their peers and performed worse on navigational tasks (Davis and Cashdan 2019), though they were still precocious compared to children in WEIRD societies. Additionally, children in both traditional populations showed higher performance on tasks of mental rotation (the ability to imagine what an object would look like if it were rotated about its axis) with more formal schooling. Children even outperformed their parents and other adults in their community with less schooling as early as 7 years old (Davis, Stack, and Cashdan 2021; Davis et al. in press). Altogether, this cross-cultural evidence suggests that early childhood environments, including the cultural institutions children are exposed to, play a crucial role in the development of spatial cognitive abilities.

The upshot is that a narrow focus on WEIRD participants has resulted in a distorted picture of our species' navigational cognition that can be seen in adult cognitive phenotypes, developmental patterns and apparent sex differences. An inclination to generalize from WEIRD people to "humans" persists among developmental psychologists and cognitive scientists despite a long history of such studies, stretching back into the 1960 s.

\subsection{Mentalizing}

Theory of mind- the ability to mentalize, or infer others' beliefs, intentions, and desires- is likely an important feature of our species' evolved psychology. Many researchers have suggested that sophisticated mentalizing abilities provided a selective advantage to individuals living in large social groups, either by facilitating success in competitive relationships or by sharpening their cultural learning abilities (Baimel et. al. 2021). Supporting this view, mentalizing abilities emerge early in development across diverse populations (Baillargeon et al. 2016; Barrett et al. 2013; Callaghan et al. 2005; Hamlin et al. 2008, 2009; Hamlin 2013a, 2013b; Robbins et al. 2017).

However, just because humans everywhere reliably develop mentalizing abilities does not mean that they do so to the same extent or in the same contexts. Instead, growing evidence suggests that social norms and institutions can shape theory of mind, giving rise to cross-cultural variation in mentalizing inclinations. WEIRD people appear to be "hyper-mentalizers", lying at the extreme end of the global spectrum (Barrett et al. 2016; Curtin et al. 2020). Although children everywhere reliably develop theory of mind, the trajectory of this development varies across societies. Notably, there is cross-cultural variation in the order of acquisition of theory of mind concepts: while WEIRD children tend to understand that others can have different beliefs before they understand that others can have different knowledge, Chinese and 
Turkish children show the opposite pattern, potentially reflecting cultural differences related to individualism versus collectivism (Selcuk et al. 2018; Wellman and Fang 2006). In addition, growing evidence suggests that Western-style formal schooling may foster an earlier development of theory of mind (Kuntoro et al. 2013; Vinden 1999, 2002; Wang et al. 2016). For example, students at Chinese-style schools in Hong Kong show delays in theory of mind relative to children at British-style schools in the same city even after controlling for socioeconomic factors (Wang et al. 2016). These findings raise the possibility that Western-style formal schooling may foster an emphasis on mentalizing.

Cross-cultural variation in conceptions of the mind may also shape the extent to which people engage in mentalizing across contexts (Willard and McNamara 2019). Anthropologists have identified six different "theories of mind" from across the ethnographic spectrum. Beyond the well-known Western secular conception, which situates the mind as an entity separate from, but causally important to, the physical world, there are a diversity of non-WEIRD approaches. Other conceptions of mind vary across multiple dimensions (Luhrmann et al. 2011, 2021), including

(1) Porousness: can minds enter other minds? (underpinning phenomena like spirit possession)

(2) Causality: do intentions play a causal role in the physical world? (underpinning many witchcraft and evil eye beliefs)

(3) Relational access: is it socially acceptable to make inferences about others' minds?

Illustrating the role of relational access, anthropologists have documented Opacity of Mind norms - rooted in the belief that other minds are fundamentally unknowable-in small-scale societies throughout the South Pacific and elsewhere (Luhrmann et al. 2011; Robbins and Rumsey 2008). Where Opacity of Mind norms operate, people feel that it is inappropriate to speculate about others' minds and children are actively socialized to deemphasize internal states and focus instead on external behaviors (e.g., crying rather than sadness: Luhrmann et al. 2011; Schieffelin 1990, 2008). Beyond simply modulating behavior, these norms shape people's tendency to engage in theory of mind. For example, compared to either Americans or Indo-Fijians (whose ancestors arrived from India as indentured servants), indigenous Fijians are less likely to use inferences about a person's false beliefs to predict their future behavior. They also report thinking less about others' internal mental states- and this accounts for the difference in performance on the false-belief task compared to Americans (McNamara et al. 2019, 2021).

Of special interest to philosophers, studies have begun to reveal striking crosscultural variation in one specific facet of mentalizing: the tendency to consider intentions and other mental states when making moral judgements. If someone took your bag after mistaking it for their own, would you judge their action as harshly as if they had purposefully stolen it? If you're WEIRD, almost certainly not. WEIRD people place heavy emphasis on an actor's intentions, even judging attempted (but unsuccessful) harms more harshly than accidental (but actual) ones (Young et al. 
2007; Young and Saxe 2008, 2009). To the WEIRD mind, it is intuitive and obvious that intentions should be central- and this is reflected in Western legal codes, which trace back to the High Middle Ages (Berman 1983; Henrich 2020).

When we look elsewhere in the world, however, the generalizability of WEIRD people's laser-like focus on mental states comes into question. Using vignettes featuring theft, physical harm, poisoning, and food taboo violations, Barrett et al. (2016) uncovered substantial variation in this tendency across a diverse sample of 10 societies. Anchoring the extremes, participants from Los Angeles and rural Ukraine judged high-intent harms much more severely than low-intent ones, while participants from Namibia and Fiji judged them to be equally bad and worthy of punishment (Barrett et al. 2016). Follow-up work confirmed that indigenous Fijians place more emphasis on outcomes than intentions when making moral judgments (McNamara et al. 2019, 2021). Interestingly, priming Fijians to think about thoughts shifts their judgments to be more intention-focused. This suggests that, under normal circumstances, Fijians may be less attuned to mental states than Westerners in making moral judgements. Deviations from the WEIRD pattern of moral judgement have also turned up in industrialized Asian societies, with Japanese participants placing less weight on intentions than US participants (Hamilton and Sanders 1992).

Although cross-cultural experimental research on this topic is rare, the ethnographic record suggests that a tendency to weigh outcomes over mental states in moral judgment has been widespread. A recent, systematic review of ethnographies found that notions of strict liability (where outcome rather than intent or motive is the primary factor in determining culpability) and corporate guilt (where guilt for crimes depends on being in the same clan or kin group as the perpetrator) appear in societies around the globe and across the spectrum of subsistence strategies (Curtin et al. 2020).

Although more research is needed to understand the sources of variation in attention to mental states during moral judgment, recent evidence indicates that kin-based institutions play a role. Researchers use the term "kinship intensity" to describe variation in how central kinship is to the formation of personal identity and social networks, noting that WEIRD societies have extremely weak kin-based institutions (Curtin et al. 2020; Henrich 2020; Schulz et al. 2019). Reanalyzing Barrett et al.'s (2016) cross-cultural data, Curtin et al. (2020) found that as kinship intensity rises, people's reliance on mental states in moral judgment declines.

Together, this body of research indicates that the WEIRD obsession with intentions when making moral judgements is not representative of humans everywhere. On the contrary, WEIRD people may lie on the extreme end of this spectrum. Consequently, scholars from WEIRD societies, or even those educated in WEIRD institutions, should distrust the generalizability of their intuitions on such matters. From this perspective, efforts to define the epistemic conditions of "moral responsibility" in philosophy (Rudy-Hiller 2019) look like formalized versions of WEIRD folk psychology. Are many philosophers doing cultural philosophy? 


\subsection{Thinking Styles}

John Locke famously claimed, without evidence, that reasoning is an innate, universal human faculty (Locke 1690). Yet, at the same time, researchers have also long recognized a vital role for culture in shaping thinking and reasoning since at least the dawn of psychology (see Cole 2003 for a valuable historical overview). Notably, the philosopher Wilhelm Wundt (1916), often considered one of the fathers of modern psychology, explicitly advocated for two psychologies - one concerning the properties of the mind universal to all humans, the other focused on the role of different cultural contexts in shaping psychological phenotypes. While Wundt's original efforts to trace the differences in reasoning among populations to the impact of "civilization" reflected the Euro-centric superiority of his era, the question of how culture shapes reasoning has persisted.

More recently, research that began in the 1960s focused on the effects of formal schooling on cognition (see Cole 1990, 2003; Rogoff 1981 for reviews). This work, which expanded on Luria's (1976) pioneering efforts in the early twentieth century, demonstrated that while there were by and large no differences in the capacities for reasoning across populations, habitual patterns of thought did vary markedly across populations and, particularly, across educational statuses (schooled v. unschooled). For instance, unschooled populations are highly unlikely to operate using abstract categories in solving a variety of problems, whether in clustering to-be-recalled items by semantic category, identifying which items do or do not belong in a set (e.g. not excluding 'log' from the set 'hatchet-log-hammer-saw' on the basis of it not being a tool) and learning rules-e.g., if in one task the correct basis of discrimination is by color, the next task is likely to also involve color discrimination (Cole 1971; Sharp et al. 1979). Moreover, even the notion of providing a definition for common objects is largely rejected by non-schooled participants (Luria 1976). While unschooled populations have been shown to be capable of using abstract categories (after some training or scaffolding), the fact that this is a highly counterintuitive approach for groups without the peculiar experience of formal (Western) schooling is salient. In other words, while many (if not all) of the operations available for reasoning may be universal, what counts as a reasonable way of thinking or the best way of thinking varies (Buchtel and Norenzayan 2008) and these differences have important effects not only on how people approach and solve problems but also on how they conceptualize the world.

Beginning in the late 1990s, researchers in psychology and cognitive science have found that — schooling aside_-culture plays an essential role in how people reason in domains that include ecology (Busch et al. 2018), social conflicts (Peng and Nisbett 1999), causal attributions (Choi et al. 1999; Li et al. 2012), stock prediction, categorization (Norenzayan et al. 2002) and moral cognition (Awad et al. 2018; Sachdeva et al. 2011). Among these, the most often discussed aspect of cross-cultural variation is undoubtedly the holistic versus analytic spectrum. Broadly speaking, this dimension captures a set of interrelated perceptual, cognitive, and reasoning differences among populations (Nisbett et al. 2001). For reasoning in particular, analytic thinking is formal (rule-based) and abstract whereas holistic thinking is relational and experience-based (Nisbett et al. 2001; Scribner 1975; Scribner and Cole 1973). 
Fig. 1 Variation in the frequency of analytic (versus holistic) responses across 31 populations. Except for the Mapuche, all participants responded online to the same Triad Task at yourm orals.org. The Mapuche data was collected using a similar triad task in one-on-one interviews. Re-drawn from Henrich (2020) with thanks to Thomas Talhelm. The black bars mark the populations most commonly sampled by researchers in the experimental behavioral sciences, though sampling is dominated by Americans, Dutch, Canadians and Brits

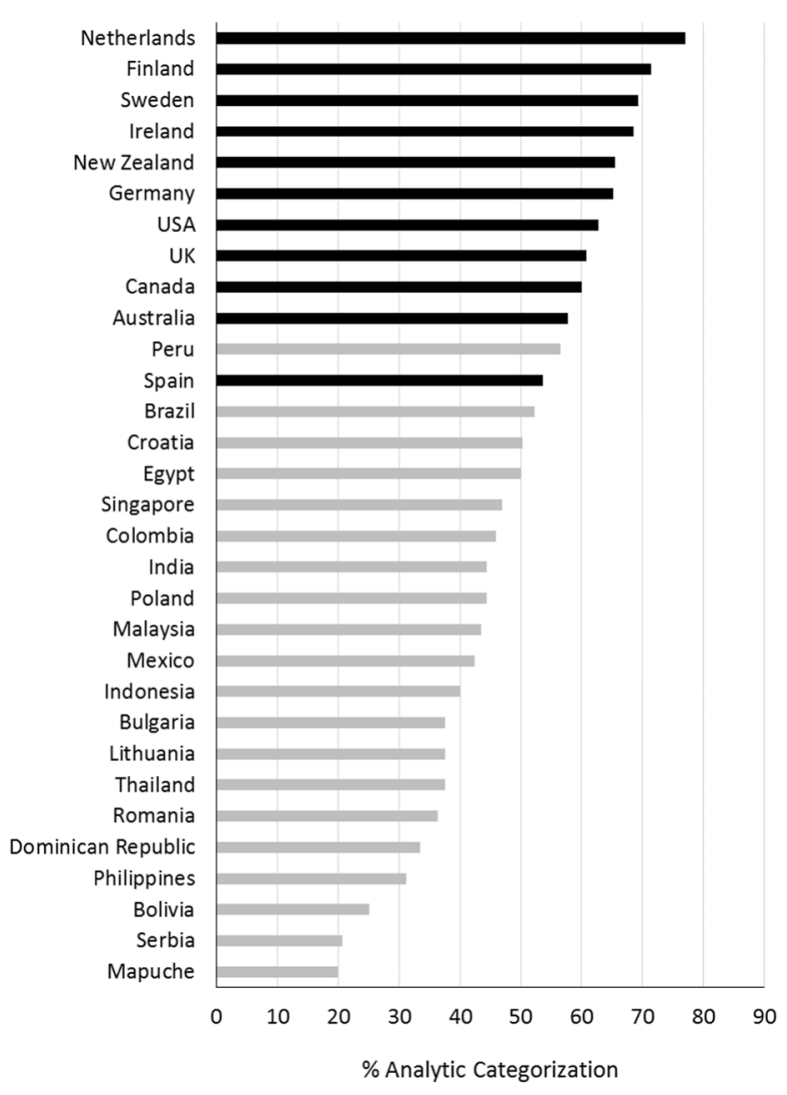

Analytical thinkers look for categories with necessary and sufficient conditions, and assign properties to individuals and objects based on category membership. By contrast, holistic thinkers focus on the relationships among individuals or objects, consider background and context, and judge similarity based on family resemblance or gestalt relationships.

Figure 1 shows the country-level variation in analytic versus holistic thinking found using the Triad Task in online samples from around the world (Henrich 2020). The Triad Task asks participants to state whether a series of targets, usually shown in images, 'go with' one of two other options. For example, participants might see a 'rabbit' and have to say whether it goes with either the 'dog' or the 'carrot.' More analytically inclined thinkers tend to put the mammals together (rabbits and dogs) while more holistically inclined people prefer the functional relationship (rabbits eat carrots). The results show substantial variation around the world, ranging from about $20 \%$ analytical responses among Serbians to nearly $80 \%$ among the Dutch. In WEIRD countries, a majority of responses favored the analytic option, while elsewhere, most other populations were holistically inclined.

Like Locke, and for psychological reasons we'll explain below, most Western intellectuals implicitly assume that their intuitions, motivations, preferences, 
emotions and ways of thinking generalize across all of humanity. But, while this is sometimes the case, we don't yet have reliable theories that tell us when and where such generalizations are safe. Philosophers should proceed with caution. What if many aspects of our reasoning abilities and judgments are influenced by cultural evolution?

\subsection{Epistemic Norms}

Epistemic norms shape what people (1) attend to when seeking out information, (2) count as evidence and (3) consider as a persuasive argument (Henderson 2020; Kauppinen 2018; Littlejohn and Turri 2014; Tomasello 2020). Epistemic norms are so-called because they govern not actions or decisions, but the identification of relevant information, the weighting of different kinds of evidence, and the evaluation of various forms of argument. This influences the formation and updating of beliefs. Some norms apply to particular epistemic activities, such as how one ought to make inferences. For example, epistemic norms regulate how one should deal with inconsistencies, interrogate the entailments of, and conflict among, one's own beliefs, and update one's beliefs in light of new observations. Other epistemic norms govern more social aspects of information handling (Brady and Fricker 2016; Goldman and O'Connor 2019), such as how much confidence to have in the testimony of different individuals or in different kinds of people based on their social identity and group membership ("respect the wisdom of your elders," "believe women," or "distrust strangers"). Others prescribe how much to trust the claims made by different institutions and their leaders, and how much authority or deference should be given to experts of different kinds: e.g., "conservatives should be skeptical of information in the mainstream media," "trust digital natives," "when it comes to vaccines, physicians and health care professionals know best").

In the modern world, Stahl et al. (2016) found that some people see reliance on "logic and evidence" in the maintenance of beliefs as a moral issue, while others do not. Those norms that govern the more social aspects of epistemic activity are perhaps most familiar. Partisan groups often adopt norms that recommend placing different levels of trust in various institutions and experts (e.g., The New York Times versus Fox News) and have different leaders that they hold in various levels of esteem (e.g., Biden versus Trump). Indeed, publicly rejecting or avowing certain beliefs can serve as an important way for individuals to visibly display their identity and signal their commitment to a particular group and its values. Such performances can serve to solidify one's standing as a group member and to enhance one's reputation and credibility within it, especially when such displays are costly in some way (Henrich 2009; Kahan et al. 2017; Schaffner and Luks 2018). Thus, there can be a tension between epistemic norms that reliably lead to true beliefs and those that effectively perform important tribal signaling functions associated with social identity and group membership.

In twenty-first century philosophy, tensions between epistemic norms tend to emerge in the context of contemporary political differences (Edenberg and Hannon 
2021; Nguyen 2020; Raymond and Kelly forthcoming; Rini 2017), but the cultural evolution of epistemic norms is an ancient problem: epistemic norms vary substantially across diverse populations and back into history. Henrich (2020), for example, discusses global variation in people's willingness to defer to elders, traditional authorities and ancient sages, and argues that these norms have shifted dramatically over the last millennium in some populations. Dovetailing with Henrich's (2020) account, the philosopher Michael Strevens (2020) has argued that the success of modern science is built around its irrational focus on the use of empirical evidence to adjudicate theories in published discourse. While authority, elegance, intuition and other epistemic sources no doubt influence scientists themselves, epistemic norms bar them from deploying these sources in formal scientific communiques.

By contrast, philosophers in many societies thought it made good sense to invoke ancient authorities or sages with 'time-tested' wisdom to convince others. For example, the Confucian philosopher Xunzi, in arguing against the use of a person's physical appearance to judge their personal characteristics or fate, starts by pointing out that physiognomy did not exist in antiquity and that learned scholars in ancient times did not talk about it (Knoblock 1988). Notably, Xunzi did later invoke empirical arguments, but the precedence of and emphasis on authority is telling: the sentence "physiognomy did not exist in antiquity" is repeated three times in the first paragraph. ${ }^{2}$

Nowadays, arguments from authority are often categorized as fallacious, even by textbooks on logic and critical thinking (Copi et al. 2018; Hansen 2015; Rudinow 2008; Walton and Koszowy 2014). The average lay person in contemporary WEIRD societies, though not necessarily aware of the details of the scientific processes in specific disciplines, nonetheless has a vague understanding that some kind of empirical inquiry is needed to generate genuine knowledge (National Science Board 2018).

Of course, one of the central consequences of adaptive cultural evolution is that venerable traditions and stable customs are indeed often imbued with implicit knowledge and a kind of wisdom. As explained above, evolutionary approaches to culture argue that humans have evolved learning mechanisms that are often selective, guided by strategies and heuristics that dispose individuals to acquire some

\footnotetext{
${ }^{2}$ Of course, in Europe, we also observe that authority and tradition often implicitly or explicitly served as the justification for particular beliefs and practices. The claim that garlic can diminish the magnetic power of magnets, for example, was passed down over millennia primarily because great ancient Roman philosophers and naturalists wrote about it (Wootton 2016). When it was eventually questioned in the seventeenth century, as modern experimental science was taking shape, we still see a strong epistemic reliance on authority: “...yet I cannot believe that so many famous Writers who have affirmed this perperty of the garlick, could be deceived; therefore I think that they had some other kinde of Load-stone, then that which we have now." (Ross 1652). Here, in an attempt to preserve the veracity of ancient writers, Ross invokes the auxiliary hypothesis that it must have been a different kind of load stone that the ancients were referring to. By contrast, the political theorist Hannah Arendt 1 1951, 1961) points out that one defining characteristic of modernity is the loss of authority. Similarly, Strevens argues that since the scientific revolution in the seventeenth century, great emphasis has been placed on experience as the ultimate way to validate knowledge claims and as a result the appeal to other epistemic sources has declined (Wootton 2016).
} 
behaviors and ideas rather than others (Cheung et al. 2011; Evans et al. 2018; Heyes 2016; Koenig and Sabbagh 2013; Laland 2004). While these selective learning abilities can generate errors in isolated episodes of individual decision-making, both empirical and theoretical work reveal how they produce adaptive practices, strategies and heuristics over generations. Cultural evolution can generate an increasingly adaptive body of practices, customs, techniques and strategies without anyone really understanding the details of how or why these "work." Consequently, traditions often embody an implicit wisdom (Boyd and Richerson 2005) that the participants themselves don't understand.

Recent philosophical work has taken up these scientific lines of thought in at least two ways. First, philosophers have asked whether or not these kinds of selective social learning heuristics can be assimilated to traditional perspectives on rationality and epistemic virtue (Funkhouser 2020; Levy and Alfano 2020; Peters 2020). Not surprisingly, humans seem to calibrate their learning heuristics in somewhat different ways in different places (Giuliano and Nunn forthcoming; Mesoudi et al. 2014). Second, philosophers focused on institutions and moral progress have begun to consider the implications of this picture for politically conservative and progressive approaches to social change (Brownstein and Kelly 2019; Buchanan and Powell 2018; Kling 2016).

\subsection{What Counts as Evidence?}

Would you consider a dream in which your teeth fell out as evidence that a close relative is going to die? This is a common belief in Southwestern China. However, if you are from a WEIRD society, chances are that you would not—in fact, most Americans barely remember their dreams as they do not view dreams as providing relevant information for future events (Kracke 1992). In stark contrast, both historical and anthropological evidence indicates that dreams have often been considered a valuable source of information that has been, and continues to be in some places, a guide to future decisions and actions (Bourguignon 1972; Hollan 1989; Lincoln 2003; Tedlock 1987). Even in societies with sophisticated literary and philosophical traditions, including both pre-modern China and ancient Greece, deciphering dreams for hidden information developed into the serious art of oneiromancy (Hong 2021; Hughes 2000). The Zhou dynasty (1046 BCE - 256 BCE), for example, had official positions for oneiromancers, and the historical record indicates that during the Han dynasty, when different divination methods didn't yield the same result, oneiromancy took precedence (from the Han Shu, Yiwenzhi (Treatise on Literature)).

Alongside dreams, the use of divination technologies has played a significant role in many, if not most, historically- and archeologically-known societies (Flad 2008; Fodde-Reguer 2014; Yi-long 2020). Although many reading this article likely view divination as a silly superstition, many philosophers and other scholars across history-from ancient Greece and Egypt to Persia and China, have viewed it as a legitimate way of gaining knowledge (Annus 2010) and the "signs" used in various divinatory practices were treated as genuine evidence for what was going to happen. Today, among the Yi in southwest China, people use the burnt cracks on sheep 
shoulder blades as an indication for whether sacrificing particular animals would appease a malicious spirit and cure an illness. Some shamans even refer to the crack signs as zhengju 证据 (Mandarin), which translates exactly as "evidence" in English (Hong and Henrich 2021). The great value that people place on divination is captured by their willingness to pay diviners substantial sums of money for their services.

What's WEIRD across human societies and back into history is not using dreams and divination as epistemic sources for important decisions. The use of dreams and divination technologies has often been endorsed by the elite and has been commonly used by Emperors and generals in statecraft and war.

\section{3 “Human" Judgment and Reasoning?}

Decades of research in cognitive science have suggested that "human reasoning" is systematically biased away from rational expectations in a variety of ways (Kahneman 2011). However, rarely does the size or direction of these biases remain constant across societies, although this fact is rarely mentioned in popular accounts, textbooks or even journal publications. Let's illustrate this with a bias that psychologists have dubbed the "Fundamental Attribution Error (Gilbert and Malone 1995), which turns out not to be so fundamental.

Consider this personal description of a motorcycle accident in India witnessed by a participant in a psychological study.

This concerns a motorcycle accident. The back wheel burst on the motorcycle. The passenger sitting in the rear jumped. The moment the passenger fell, he struck his head on the pavement. The driver of the motorcycle-who is an attorney - as he was on his way to court for some work, just took the passenger to a local hospital and went on and attended to his court work. I personally feel the motorcycle driver did a wrong thing. The driver left the passenger there without consulting the doctor concerning the seriousness of the injury-the gravity of the situation-whether the passenger should be shifted immediately - and he went on to the court. So ultimately the passenger died.

Why do you think the driver left the passenger at the hospital without staying to consult about the seriousness of the passenger's injury? One middle-class American explained, "The driver is obviously irresponsible; the driver was in a state of shock; the driver is aggressive in pursuing career success."

Now, contrast the American's description with that of a middle-class Hindu participant in the city of Mysore, in southern India: "It was the driver's duty to be in court for the client whom he's representing; secondly, the driver might have gotten nervous or confused; and thirdly, the passenger might not have looked as serious as he was."

The Hindu participant focused on the lawyer's roles and responsibilities, while considering situational factors that might explain his behavior. By contrast, the American focused more on the lawyer's internal, dispositional states-he's "irresponsible" and "aggressively" overambitious. By the Hindu's account, the lawyer 


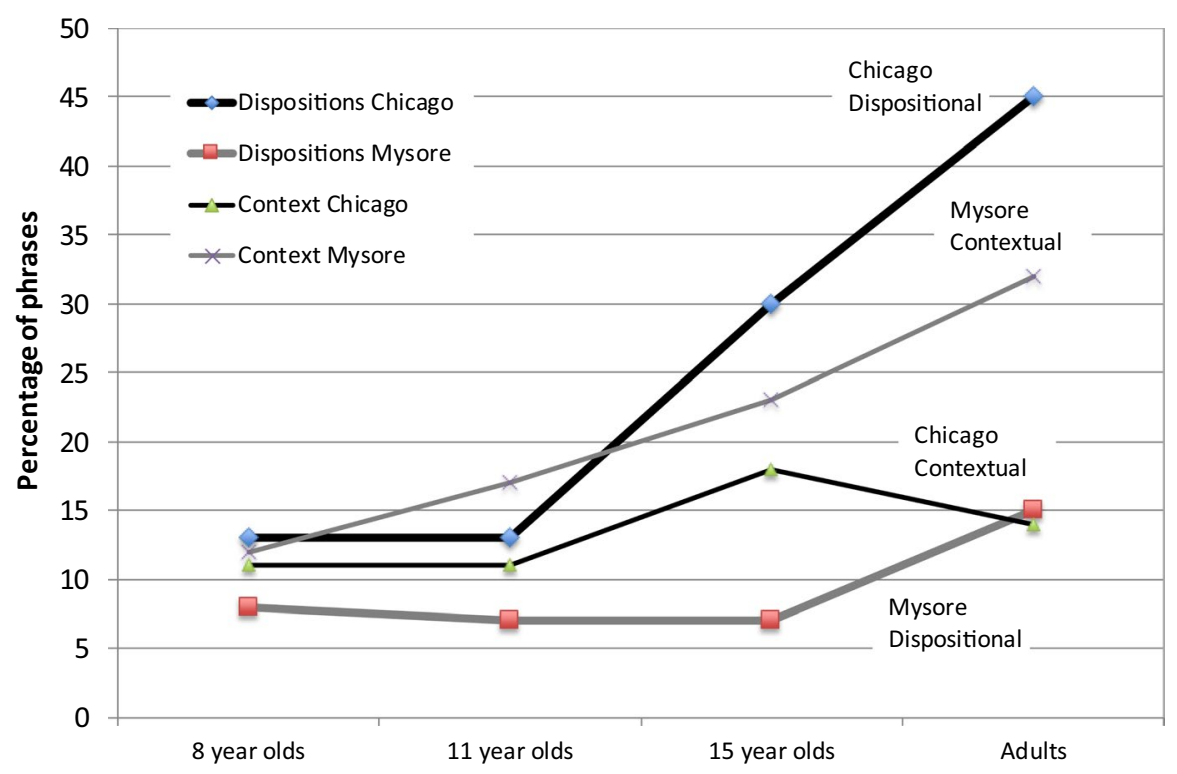

Fig. 2 The development of dispositional versus contextual attributions for wrongdoing in Mysore (India) and Chicago (US). The black lines mark Chicago populations while grey indicates Mysore. The thicker lines indicate dispositional attributions while the thinner mark contextual attributions. These data were gleaned from Miller (1984)

leaves the injured cyclist because of his responsibilities to his client-a relationship and responsibility. For the American, the lawyer departs out of concern that dillydallying might damage his professional advancement—his personal achievements.

This story was part of an investigation by the psychologist Joan Miller (1984). Miller asked people in Chicago and Mysore to describe two situations in which someone they knew well did something that they (the participant) considered wrong. Participants were also asked to explain why it was wrong. Joan's research team coded the contents of these narrations according to whether people used (a) contextual factors like social norms or relationships or (b) dispositional characteristics, such as references to personality traits, attributes (honesty) or competence. In both Mysore and Chicago, participants were middle-class adults as well as children and adolescents, ages 8,11 and 15 years old. ${ }^{3}$

Figure 2 shows the development of both contextual/relational and dispositional attributions for the situations described by people from both cities. In middle childhood, children in both cities are pretty similar, although the 8-year-old Chicago kids are already producing dispositional attributions about $15 \%$ of the time compared to $8 \%$ for their peers in Mysore. However, despite their similar starting points, the developmental trajectories for the two populations then diverge sharply. In Chicago,

\footnotetext{
3 Miller observed similar effects for prosocial situations, though dispositional attributions are generally less pronounced. See Heine (2012) for discussion.
} 
the frequency of dispositional attributions-like 'dishonest', 'sincere' or 'aggressive'-balloons to $45 \%$. For the same developmental period, the frequency of contextual references remains relatively flat, going from $11 \%$ in the 8 -year-olds to $14 \%$ in adults. Meanwhile, in Mysore, contextual attributions rise from $12 \%$ in 8 -year olds to $32 \%$ in adults while dispositional attributions only increase from $8 \%$ to $15 \%$.

What's going on? Is this some Indian peculiarity? No. It's the people in Chicago who are peculiar when placed in a global and historical perspective. A wide range of other evidence, much of it collected since Miller's early work, confirms that WEIRD people are particularly inclined toward dispositional inferences (Chiu et al. 2000; Heine 2016; Nisbett 2003; Smith and Apicella 2020). The centrality of dispositions in the social sciences, using acontextual traits like 'extroverted', 'inequality averse,' or 'moral', reflect WEIRD biases in thinking. ${ }^{4}$

Dispositional attributional biases are just the tip of an iceberg of cognitive variation in this domain. Most of the decision-making and judgment heuristics and biases heralded by psychologists and behavioral economists (Kahneman 2011) vary across societies, with some disappearing entirely or even reversing direction. These include overconfidence (Yates et al. 1997, 1998), risk aversion (Vieider et al. 2015), the gambler's fallacy (Ji et al. 2015), the hot hand fallacy, the representativeness heuristic (Spina et al. 2010b), neglecting regression to the mean (Spina et al. 2010a), functional fixity (Pope et al. 2018) and the endowment effect. Among WEIRD participants, for example, overconfidence biases in which participants overate their own abilities are robust, persistent and well-replicated. However, across both behavioral domains and diverse populations, researchers have found that population-level variation includes cases of underconfidence (Muthukrishna et al. 2018b). Similarly, not only does the strength of risk aversion vary across populations for the identical monetary gambles (Falk et al. 2018), but some societies are risk prone (not risk averse) in absolute terms (Henrich and McElreath 2002). Similarly, the famous endowment effect, in which participants place greater value on things they themselves own, does not appear in Tanzanian hunter-gatherers living their traditional lifestyle (Apicella et al. 2014) and is substantially muted among Japanese participants compared to Americans (Maddux et al. 2010). All of these patterns hold when real money or other goods are at stake and decisions impact people's payoffs.

In summary, faced with the identical information in relatively simple, incentivized problems, people from different societies deploy different heuristics and biases to arrive at different judgments and decisions. In fact, while many heuristics and biases have not been studied cross-culturally in any serious way, it is difficult to find examples that do not show important variation.

\footnotetext{
4 Interestingly, Miller did find that a Christian community of Indians in Mysore did make more dispositional attributions (30\%) than either lower or middle-class members of the Hindu majority. In fact, they were about halfway between the Hindu majority and Chicago. Several researchers have argued that some forms of Christianity encourage dispositional thinking (Cohen and Rozin 2001; Henrich 2020; Li et al. 2012).
} 


\section{WEIRD Languages?}

A growing body of evidence suggests that language shapes our attention, habits of thought, categorizations, mental abilities and perceptions (Deutscher 2010). Languages, of course, also provide us with a wide range of cognitive tools-e.g., concepts and categories - that influence how we parse the world and solve problems. Languages, for example, vary in how they reference direction and orient speakers and listeners in space. Some languages require speakers to track absolute directions - as in north, south, east and west-for all spatial references. Other languages provide multiple coordinate systems, including object-centered systems like 'right' and 'left', and relative coordinate systems that include the observer ("she's on the left of the flagpole"). Growing up immersed in languages with different reference systems creates quite different cognitive demands, which cultivate impressive cognitive skills that are not easily mastered later in life by those who grew up elsewhere (Haun et al. 2006; Levinson 2003).

Categories and concepts matter. Compared to agriculturalists living in the same environment, hunter-gatherers possess a rich repertoire of 'basic' olfactory categories that allow them to abstractly describe and distinguish a wide range of scents (Majid and Kruspe 2018). At the same time, it's not uncommon for such small-scale societies to have between 0 and 3 basic color terms, and no explicit term or concept for 'color' as a separate dimension (no easy way to say, 'what color is it?'). If they do have 2 color terms, they are expansive versions of black and white. If they have a third, it's usually an expansive red (Everett 2005; Kay and Regier 2003, 2006; Lindsey et al. 2015; Wierzbicka 2013). Of course, while nearly all human populations perceive color variation (Sacks 2012), ${ }^{5}$ the presence of terminological distinctions does impact performance in various cognitive tasks (Goldstein et al. 2009, 2009; Lucy 1996). All this suggests that a hunter-gatherer philosopher would be unlikely to claim that scent was the least important of the senses-her language would likely have few or no abstract color terms but many abstract scent terms.

Grammar shapes what we pay attention to because different grammars variously require speakers to track other people's social status (e.g., choosing between formal and informal pronouns), gender (and how many genders?), time (e.g., mandatory future tense), number (e.g., 'we' involving 2, 3 or 4?), absolute direction and evidentiality (e.g., did you see it or just hear about it?). Like any daily training routine, such pervasive cognitive demands automate our attention and ingrain particular ways of processing information. At the same time, different vocabularies highlight particular concepts and provide ready ways of parsing and interpreting the world. While debates persist regarding the impact of language on thought, a growing body of evidence that stretches across several disciplines is revealing how certain features of language influence important domains of behavior. As unlikely as it may seem, economists have argued that languages with a mandatory future tense induce people to think about the future more, resulting

\footnotetext{
5 Interestingly, there may be genetic variation that influences our ability to perceive specific regions of the color spectrum and this may impact the presence of color terms for 'blue' (Brown and Lindsey 2004).
} 
in greater saving and investments for the future (Chen 2021; c.f. Roberts et al. 2015). Similarly, evidence suggests that gendered languages might inhibit the participation of women in the labor force (Gay et al. 2018; c.f. Gotti et al. 2021) and shape how people characterize non-animate referents (like furniture, celestial bodies or tools) (Williams et al. 2021). Meanwhile, cognitive scientists have long argued that languages influence how we think about time (Boroditsky 2011, 2018) and agency (Fausey and Boroditsky 2010; Fausey and Boroditsky 2010). Broadly, understanding how grammar shapes our attention and thinking would seem crucial to philosophical debates about language, policy and social change (Dembroff and Wodak 2018).

While some of the variation across languages might be a by-product of language-specific dynamics, there is evidence for extra-linguistic factors steering the evolution of languages (Henrich 2016), including ecological conditions (Everett et al. 2015; Forker 2020), religious taboos, social transmission (Blasi et al. 2017) and social structure (Foley 1997; Lupyan and Dale 2010). This further reinforces the association between the non-linguistic traits that characterize WEIRD societies with the linguistic properties of their languages (Galor and Sarid 2018).

Such evidence suggests that if scholars relied heavily on one language or perhaps a set of related languages, biases could arise in how they approach and analyze many kinds of questions, and even what questions they ask. Many concepts, like "morality" and "right and wrong" don't have corresponding concepts in other languages (Wierzbicka 2013). Of course, reliance on such concepts is especially worrisome if "research" involves probing and refining one's own (native speaker) intuitions about such concepts (Stich and Mizumoto forthcoming)—probe your intuitions about the importance of scents versus colors?

Of course, research must be done in some language, so perhaps the languages used by philosophers and others are as representative as any other language? Well, it turns out that English is unusual among Germanic languages and Germanic languages are unusual among Indo-European languages (McWhorter 2008). Modern English has by far the largest vocabulary of any language, but a relatively simple grammatical morphology even compared to other European languages (Bentz et al. 2016; Henrich 2016). For example, English grammar includes borrowed features, including elements from Celtic (probably) like the 'meaningless do' (Do you want to go to the store?). Illustrating its simplicity, English has grammaticalized distinctions only between simple and perfect past tense (watched/had watched), but in about $20 \%$ of the world's languages past tense usage depends on the relative time interval between the utterance and the topic. For instance, in the Peruvian Amazon, Yagua has five such distinctions: the grammar distinguishes between events that have happened a few hours, one day, a few weeks, a few months, or in a distant past of the time in which the utterance is produced (de Haan 2010). The same holds for other domains such as spatial reference: while English uses a simple this-that distinction for overall proximity, many languages code for proximity in both the horizontal and vertical dimensions (Forker 2020). For number, English differentiates singular from plural in the form of nouns while many other languages include dedicated forms for two, three or a few referents as well (Acquaviva 2017). Finally, English has a relatively large 
number of phonemes and vowels as well as among the highest informational content per word of European languages (Muthukrishna and Henrich 2016).

Of course, the lack of a grammaticalized distinction does not mean that English speakers are unable to craft more specific references. For example, nuanced temporal distinctions can be introduced through adverbs and adverbial phrases ("I worked until late yesterday") and number can be conveyed through numerals ("They came across with three lions in their safari"). However, mounting evidence suggests the presence or absence of mandatory grammatical distinctions have observable cognitive and behavioral implications because they compel our attention (Almoammer et al. 2013; Thoma and Tytus 2018).

Some have even argued that English may be among the least representative languages vis-à-vis the kinds of languages that our species has been using throughout our deep evolutionary history (Henrich 2016). For example, there's both empirical and theoretical reasons to suspect that the sizes of speaker communities and the number of adult language learners may impact features like phoneme inventories, complex inflectional morphologies and vocabulary sizes (Trudgill 2011; Atkinson 2011; Hay and Bauer 2007). English has, as noted, the largest community of speakers for any language in human history, with Mandarin in second place, trailing with several hundred million fewer speakers. By contrast, there's little reason to suspect that ancestral languages had more than a few thousand speakers. Similarly, for a variety of reasons, the languages of small-scale societies tend to have few or no color terms, few numerals and, in some circumstances, no explicit embedding devices (but used parataxis and context). Historical linguists have shown how embedding devices have evolved culturally over recent millennia and, more recently, have been shaped by literacy and schooling (Deutscher 2005; Henrich 2016). In the modern world, English speakers possess an unbounded counting system, a rich array of embedding tools and a package of 11 basic color terms (but no basic scent terms). The age at which American children master their color terms has been declining over the last seventy years-going back as far as the data stretches. However, by contrast with most English speakers (urbanites), people in horticultural-foraging societies tend to possess richer olfactory and biological species taxonomies (Atran et al. 2004). Finally, extrapolating ecological and dietary associations suggest that the earliest human languages were potentially tonal, making them distinct from all major European language (Everett et al. 2016; Blasi et al. 2019). Thus, there are a variety of reasons to be particularly skeptical about the generalizability of any linguistic, psychological or philosophical intuitions rooted in English.

\section{Conclusion}

In the emerging interdisciplinary field of Cultural Evolution, a rising tide of theoretical and empirical work that has emerged over the last four decades makes a strong case that humans are a cultural species, that both our minds and bodies arose as products of the interaction between genes and culture over hundreds of thousands or even millions of years. Cultural evolutionists have argued that our capacities for cumulative cultural evolution, the hallmark of our species, produces many of the 
tools, techniques and heuristics that we think and reason with-ready examples include number systems, fractions, physical concepts (e.g., elastically stored energy and wheels) and perceptual categories (abstract color and scent terms). Social norms and daily demands mean that people habitualize the use of these in ways that recede into the background and become part of how we automatically perceive and process the world. Specifically, humans have evolved genetically to mold our minds and brains to culturally-constructed worlds - adapting to their diverse incentives, affordances, and constraints. In this paper, we provided an introductory review of work in this field, highlighting domains that might be of particular interest to philosophers. However, readers should bear in mind that this has been a selective review that represents only the tip of an empirical iceberg that continues to grow (Apicella et al. 2020; Heine 2016; Henrich 2020).

Perhaps the most important development in this field has been the production and testing of theories to explain contemporary psychological variation and, methodologically, the integration of quantitative historical data into these analyses (Muthukrishna et al. 2021). For example, Schulz et al. (2019) and Enke (2019) have linked a wide range of psychological outcomes, including analytic thinking, trust in strangers and individualism, to kin-based institutions-family organization. Talhelm et al. (Talhelm 2020; Talhelm et al. 2014) have examined the role of paddy rice agriculture in explaining analytic thinking, interpersonal loyalty and self-concepts. Focusing on variation in gender inequality and other sex differences, economists have isolated the influence of large-animal pastoralism, plough-based agriculture and matrilineal kinship (Alesina et al. 2013; Becker n.d.; Giuliano 2018; Gneezy et al. 2009; Gong and Yang 2012; Hoffman et al. 2011). By providing theories, rooted in historical processes, these approaches effectively address lingering concerns that the observed psychological variation developed recently or simply represents 'shallow' responses to experimental protocols or interview questions. If these effects were shallow and/or ephemeral, how is it that we can explain important swaths of the variation with historical data from centuries past?

While the evolutionary approach discussed here leaves ample room for innate or reliably developing features of human psychology, both the theory and evidence synthesized here undermine the view that many aspects of our minds are cognitiveimpenetrable (Fodor 1983). In the domain of perception alone, ample evidence indicates that cultural evolution has made us myopic (literally, they need glasses), reduced our underwater visual acuity (Gislen et al. 2003), decreased our sensitivity to odors, sharpened our color identification, altered our objective judgments of lines (Park et al. 2016), elevated our susceptibility to some visual illusions (Segall et al. 1966), and nearly eliminated lateral mirror invariance (seeing "b" and "d" as the same; Henrich 2020). Culture has also shaped the heuristics and biases that influence our decision-making and manipulated our motivations and preferences related to everything from food, pain and sexual attraction to fairness, trust and cooperation with strangers (Ensminger and Henrich 2014; J. Henrich 2016). While perception, morality and rationality are all rooted in genetically evolved features of mind, the cognitive phenotypes highlighted and debated by philosophers are more likely cultural kludges, or cultural adaptations to particular environments, than innate structures (McCauley and Henrich 2006; Stich 2006). 
It's now clear that much of what we find in social and developmental psychology textbooks is simply the "cultural psychology" of WEIRD people and represents a quantitative ethnographic description of how a particular population thinks, remembers, feels and reasons rather than a systematic study of human nature or our species' evolved psychology. Philosophers, by confronting the WEIRD people problem and harnessing the tools found in Cultural Evolution, can avoid perpetuating a peculiar brand of "cultural philosophy," rooted in WEIRD intuitions, and instead begin to construct a philosophy for Homo sapiens.

\section{Declarations}

Conflict of Interest None

\section{References}

Acquaviva, P. (2017). Number in Language. In Oxford Research Encyclopedia of Linguistics. https://doi. org/10.1093/acrefore/9780199384655.013.61.

Alesina, A.F., P. Giuliano, and N. Nunn. 2013. On the origins of gender roles: Women and the plough. The Quarterly Journal of Economics 128 (2): 469-530.

Almoammer, A., J. Sullivan, C. Donlan, F. Marusic, R. Zaucer, T. O’Donnell, and D. Barner. 2013. Grammatical morphology as a source of early number word meanings. Proceedings of the National Academy of Sciences 110 (46): 18448-18453. https://doi.org/10.1073/pnas.1313652110.

Annus, A. (2010). Divination and interpretation of signs in the ancient world. In Oriental Institute Seminars.

Apicella, C.L., E.M. Azevedo, N.A. Christakis, and J.H. Fowler. 2014. Evolutionary origins of the endowment effect: Evidence from hunter-gatherers. American Economic Review 104 (6): 17931805. https://doi.org/10.1257/aer.104.6.1793.

Apicella, C., A. Norenzayan, and J. Henrich. 2020. Beyond WEIRD: A review of the last decade and a look ahead to the global laboratory of the future. Evolution and Human Behavior 41 (5): 319-329. https://doi.org/10.1016/j.evolhumbehav.2020.07.015.

Arendt, H. 1951. The burden of our time. Secker \& Warburg.

Arendt, H. 1961. The concept of history: Ancient and modern. Between Past and Future 89.

Atkinson, Q.D. 2011. Phonemic diversity supports a serial founder effect model of language expansion from Africa. Science 332 (6027): 346-349.

Atran, S., D.L. Medin, and N. Ross. 2004. Evolution and devolution of knowledge: A tale of two biologies. Journal of the Royal Anthropological Institute 10 (2): 395-420.

Awad, E., S. Dsouza, R. Kim, J. Schulz, J. Henrich, A. Shariff, J.-F. Bonnefon, and I. Rahwan. 2018. The moral machine experiment. Nature 563 (7729): 59-64. https://doi.org/10.1038/s41586-018-0637-6.

Baillargeon, R., R.M. Scott, and L. Bian. 2016. Psychological reasoning in infancy. Annual Review of Psychology 67 (1): 159-186. https://doi.org/10.1146/annurev-psych-010213-115033.

Baimel, A., M. Juda, S. Birch and J. Henrich. 2021. Machiavellian strategist or cultural learner? Mentalizing and learning over development in a resource-sharing game. Evolutionary Human Sciences 3. https://doi.org/10.1017/ehs.2021.11.

Bandura, A. 1977. Social learning theory. Prentice Hall.

Barhorst-Cates, E.M., C. Meneghetti, Y. Zhao, F. Pazzaglia, and S.H. Creem-Regehr. 2021. Effects of home environment structure on navigation preference and performance: A comparison in Veneto, Italy and Utah, USA. Journal of Environmental Psychology 101580.

Barrett, H.C., and J. Broesch. 2012. Prepared social learning about dangerous animals in children. Evolution and Human Behavior 33 (5): 499-508. 
Barrett, H.C., T. Broesch, R.M.M. Scott, Z.J. He, R. Baillargeon, D. Wu, M. Bolz, J. Henrich, P. Setoh, J.X. Wang, and S. Laurence. 2013. Early false-belief understanding in traditional non-Western societies. Proceedings of the Royal Society B: Biological Sciences 280 (1755): 1-6.

Barrett, H.C., A. Bolyanatz, A.N. Crittenden, D.M.T. Fessler, S. Fitzpatrick, M. Gurven, J. Henrich, M. Kanovsky, G. Kushnick, A. Pisor, B.A. Scelza, S. Stich, C. von Rueden, W.Y. Zhao, and S. Laurence. 2016. Small-scale societies exhibit fundamental variation in the role of intentions in moral judgment. Proceedings of the National Academy of Sciences of the United States of America 113 (17): 4688-4693.

Barwich, A. S. (2020). Smellosophy: What the nose tells the mind. Harvard University Press. https:// books.google.com/books?id=7lnhDwAAQBAJ

Becker, A. (n.d.). On the economic origins of restrictions on Women's sexuality. CESifo working paper, 7770. https://ssrn.com/abstract=3432818

Begg, P.R. 1954. Stone age man's dentition: With reference to anatomically correct occlusion, the etiology of malocclusion, and a technique for its treatment. American Journal of Orthodontics 40 (7): 517-531.

Bentz, C., T. Soldatova, A. Koplenig and T. Samardžić. 2016. A comparison between morphological complexity measures: typological data vs. language corpora.

Berman, H.J. 1983. Law and revolution: The formation of the Western legal tradition. Harvard University Press.

Berry, J.W. 1966. Temne and Eskimo perceptual skills. International Journal of Psychology 1 (3): 207229. https://doi.org/10.1080/00207596608247156.

Berry, J.W. 1968. Ecology, perceptual development and the Mueler-Lyer illusion. British Journal of Psychology 59: 205-210.

Birch, L.L. 1987. Children's food preferences: Developmental patterns and environmental influences. Annals of Child Development 4: 171-208.

Blake, P.R., J. Corbit, T.C. Callaghan, and F. Warneken. 2016. Give as I give: Adult influence on children's giving in two cultures. Journal of Experimental Child Psychology 152: 149-160. https://doi. org/10.1016/j.jecp.2016.07.010.

Blasi, D.E., S.M. Michaelis, and M. Haspelmath. 2017. Grammars are robustly transmitted even during the emergence of creole languages. Nature Human Behaviour.

Blasi, D.E., S. Moran, S.R. Moisik, P. Widmer, D. Dediu, and B. Bickel. 2019. Human sound systems are shaped by post-Neolithic changes in bite configuration. Science 363 (6432): eaav3218. https://doi. org/10.1126/science.aav3218.

Boroditsky, L. 2011. How languages construct time. Space, Time and Number in the Brain: 333-341. https://doi.org/10.1016/B978-0-12-385948-8.00020-7.

Boroditsky, L. 2018. Language and the construction of time through space. Trends in Neurosciences 41 (10): 651-653. https://doi.org/10.1016/j.tins.2018.08.004.

Bourguignon, E. 1972. Dreams and altered states of consciousness in anthropological research.

Boyd, R. 2017. A different kind of animal: How culture transformed our species. Princeton University Press.

Boyd, R., and P.J. Richerson. 2005. The origin and evolution of cultures. Oxford University Press.

Boyd, R., H. Gintis, and S. Bowles. 2010. Coordinated punishment of defectors sustains cooperation and can proliferate when rare. Science 328 (5978): 617-620.

Boyd, R., P.J. Richerson, and J. Henrich. 2011. Rapid cultural adaptation can facilitate the evolution of large-scale cooperation. Behavioral Ecology and Sociobiology 65 (3): 431-444.

Brady, M., \& Fricker, M. (Eds.). (2016). The epistemic life of groups: Essays in the epistemology of collectives. Oxford University Press.

Bramble, D.M., and D.E. Lieberman. 2004. Endurance running and the evolution of Homo. Nature 432 (7015): 345-352.

Bremner, A.J., M.J. Doherty, S. Caparos, J. de Fockert, K.J. Linnell, and J. Davidoff. 2016. Effects of culture and the urban environment on the development of the Ebbinghaus illusion. Child Development 87 (3): 962-981. https://doi.org/10.1111/cdev.12511.

Brown, A.M., and D.T. Lindsey. 2004. Color and language: Worldwide distribution of Daltonism and distinct words for “blue.”. Visual Neuroscience 21: 409-412.

Brownstein, M., and D. Kelly. 2019. Review of the evolution of moral Progress: A biocultural theory by Allen Buchanan and Russell Powell. British Journal for the Philosophy of Science Review of Books 1 . 
Buchanan, A., and R. Powell 2018. The evolution of moral Progress: A biocultural theory. Oxford University Press. https://books.google.com/books?id=6AJfDwAAQBAJ

Buchtel, E.E., and A. Norenzayan. 2008. Which should you use, intuition or logic? Cultural differences in injunctive norms about reasoning. Asian Journal of Social Psychology 11 (4): 264-273.

Busch, J.T.A., R.E. Watson-Jones, and C.H. Legare. 2018. Cross-cultural variation in the development of folk ecological reasoning. Evolution and Human Behavior. https://doi.org/10.1016/j.evolhumbeh av.2018.02.004.

Callaghan, T., P. Rochat, A. Lillard, M.L. Claux, H. Odden, S. Itakura, S. Tapanya, and S. Singh. 2005. Synchrony in the onset of mental-state reasoning-Evidence from five cultures. Psychological Science 16 (5): $378-384$.

Campbell, C.E., and B.I. Strassmann. 2016. The blemishes of modern society?: Acne prevalence in the Dogon of Mali. Evolution, Medicine, and Public Health 2016 (1): 325-337. https://doi.org/10. 1093/emph/eow027.

Cashdan, E., F.W. Marlowe, A.N. Crittenden, C. Porter, and B.M. Wood. 2012. Sex differences in spatial cognition among Hadza foragers. Evolution and Human Behavior 33 (4): 274-284.

Cashdan, E., K.L. Kramer, H.E. Davis, L. Padilla, and R.D. Greaves. 2016. Mobility and navigation among the Yucatec Maya. Human Nature 27 (1): 35-50.

Chen, M.K. 2021. The effect of language on economic behavior: Evidence from savings rates. Health Behaviors, and Retirement Assets. 43.

Cheng, J.T., C. Anderson, E.R. Tenney, S. Brion, D.A. Moore, and J.M. Logg. 2020. The social transmission of overconfidence. Journal of Experimental Psychology: General. https://doi.org/10.1037/ xge0000787.

Cheung, B.Y., M. Chudek, and S.J. Heine. 2011. Evidence for a sensitive period for acculturation: Younger immigrants report acculturating at a faster rate. Psychological Science 22 (2): 147-152.

Chiu, C., M.W. Morris, Y. Hong, and T. Menon. 2000. Motivated cultural cognition: The impact of implicit cultural theories on dispositional attribution varies as a function of need for closure. Journal of Personality and Social Psychology 78 (2): 247-259. https://doi.org/10.1037/0022-3514.78.2. 247.

Choi, I., R.E. Nisbett, and A. Norenzayan. 1999. Causal attribution across cultures: Variation and universality. Psychological Bulletin 125 (1): 47-63. https://doi.org/10.1037/0033-2909.125.1.47.

Chudek, M., and J. Henrich. 2010. Culture-gene coevolution, norm-psychology, and the emergence of human Prosociality. Trends in Cognitive Sciences 15 (5): 218-226.

Chudek, M., P. Brosseau, S. Birch, and J. Henrich. 2013. Culture-gene coevolutionary theory and children's selective social learning. In The development of social cognition, ed. M. Banaji and S. Gelman. Oxford.

Cohen, A.B., and P. Rozin. 2001. Religion and the morality of mentality. Journal of Personality and Social Psychology 81 (4): 697-710. https://doi.org/10.1037//0022-3514.81.4.697.

Cole, M. 1990. Cognitive development and formal schooling: The evidence from cross-cultural research. In In Vygotsky and education: Instructional implications and applications of sociohistorical psychology, 89-110. Cambridge University Press.

Cole, M. 2003. Cultural psychology: A once and future discipline (6. Printing). Belknap Press of Harvard Univ. Press.

Cole, M. (Ed.). (1971). The cultural context of learning and thinking: An exploration in experimental anthropology. Basic Books.

Coluccia, E., and G. Louse. 2004. Gender differences in spatial orientation: A review. Journal of Environmental Psychology 24 (3): 329-340.

Copi, I.M., C. Cohen, and V. Rodych. 2018. Introduction to logic. Routledge.

Cordain, L., S.B. Eaton, J. Brand Miller, S. Lindeberg, and C. Jensen. 2002. An evolutionary analysis of the aetiology and pathogenesis of juvenile-onset myopia. Acta Ophthalmologica Scandinavica 80 (2): 125-135. https://doi.org/10.1034/j.1600-0420.2002.800203.x.

Crittenden, A.N., A. Farahani, K.N. Herlosky, T.R. Pollom, I.A. Mabulla, I.T. Ruginski, and E. Cashdan. 2021. Sex differences in harm avoidance and mobility in middle childhood and early adolescence among Hadza foragers. Human Nature.

Curtin, C.M., H.C. Barrett, A. Bolyanatz, A.N. Crittenden, D.M.T. Fessler, S. Fitzpatrick, M. Gurven, M. Kanovsky, G. Kushnick, S. Laurence, A. Pisor, B. Scelza, S. Stich, C. von Rueden, and J. Henrich. 2020. Kinship intensity and the use of mental states in moral judgment across societies. Evolution and Human Behavior 41 (5): 415-429. https://doi.org/10.1016/j.evolhumbehav.2020.07.002. 
Davis, H.E., and E. Cashdan. 2019. Spatial cognition, navigation, and mobility among children in a forager-horticulturalist population, the Tsimané of Bolivia. Cognitive Development 52: 100800. https://doi.org/10.1016/j.cogdev.2019.100800.

Davis, H.E., J. Stack, and E. Cashdan. 2021. Cultural change reduces gender differences in mobility and spatial ability among forager-pastoralist children, the Twa of northern Namibia. Human Nature.

Davis, H.E., M.D. Gurven, and E. Cashdan. in press. Navigational experience and the preservation of spatial abilities into old age among a tropical forager-horticulturalist population. Topics in Cognitive Science.

de Haan, F. 2010. Typology of tense, aspect, and modality systems. In The Oxford Handbook of Linguistic Typology. https://doi.org/10.1093/oxfordhb/9780199281251.013.0021.

Dembroff, R., and D. Wodak. 2018. He/she/they/ze, 5. Ergo: An Open Access Journal of Philosophy.

Deutscher, G. 2005. The unfolding of language: An evolutionary tour of mankind's greatest invention (13811382; 1st ed.). Metropolitan Books. http://www.loc.gov/catdir/enhancements/fy0619/20040 65607-b.html http://www.loc.gov/catdir/enhancements/fy0619/2004065607-d.html http://www.loc. gov/catdir/enhancements/fy0619/2004065607-s.html

Deutscher, G. 2010. Through the language glass: Why the world looks different in other languages (16050008; 1st ed.). Metropolitan Books/Henry Holt and Co.

Edenberg, E., and M. Hannon 2021. Political epistemology. OUP Oxford. https://books.google.com/ books?id=ORUuEAAAQBAJ

Enke, B. 2019. Kinship, cooperation, and the evolution of moral systems*. The Quarterly Journal of Economics 134 (2): 953-1019. https://doi.org/10.1093/qje/qjz001.

Ensminger, J., \& Henrich, J. (Eds.). (2014). Experimenting with social norms: Fairness and punishment in cross-cultural perspective. Russell Sage Press.

Evans, C.L., K.N. Laland, M. Carpenter, and R.L. Kendal. 2018. Selective copying of the majority suggests children are broadly "optimal-" rather than "over-" imitators. Developmental Science 21 (5): 1-10. https://doi.org/10.1111/desc.12637.

Everett, D.L. 2005. Cultural constraints on grammar and cognition in Piraha-Another look at the design features of human language. Current Anthropology 46 (4): 621-646.

Everett, C., D.E. Blasi, and S.G. Roberts. 2015. Climate, vocal folds, and tonal languages: Connecting the physiological and geographic dots. Proceedings of the National Academy of Sciences. https://doi.org/10.1073/pnas.1417413112.

Everett, C., D.E. Blasi, and S.G. Roberts. 2016. Language evolution and climate: the case of desiccation and tone. Journal of Language Evolution 1 (1): 33-46.

Falk, A., A. Becker, T. Dohmen, B. Enke, D. Huffman, and U. Sunde. 2018. Global Evidence on Economic Preferences*. The Quarterly Journal of Economics 133 (4): 1645-1692. https://doi.org/ 10.1093/qje/qjy013.

Fausey, C., and L. Boroditsky. 2010. Constructing agency: The role of language. Frontiers in Psychology 1 (162).

Fausey, C., and L. Boroitsky. 2010. Who dunnit? Cross-linguistic differences in eye-witness memory. Psychonomic Bulletin and Review 18 (1): 150-157.

Flad, R.K. 2008. Divination and power. Current Anthropology. https://doi.org/10.1086/588495.

Fodde-Reguer, A.-A. 2014. Divining Bureaucracy: Divination Manuals as Technology and the Standardization of Efficacy in Early China [PhD thesis]. the University of Michigan.

Fodor, J.A. 1983. The modularity of mind: An essay on faculty psychology. MIT Press.

Foley, W.A. 1997. Anthropological linguistics: An introduction. Blackwell Publishers.

Forker, D. 2020. Elevation as a grammatical and semantic category of demonstratives. Frontiers in Psychology 11. https://doi.org/10.3389/fpsyg.2020.01712.

Funkhouser, E. 2020. A tribal mind: Beliefs that signal group identity or commitment. Mind \& Language. https://doi.org/10.1111/mila.12326.

Galea, L.A.M., and D. Kimura. 1993. Sex differences in route-learning. Pers. Indiv. Diff. 14 (1): 53-65.

Galor, O., \& Sarid, A. (2018). Geographical origins of language structures.

Gandhi, T., A. Kalia, S. Ganesh, and P. Sinha. 2015. Immediate susceptibility to visual illusions after sight onset. Current Biology 25 (9): R358-R359. https://doi.org/10.1016/j.cub.2015.03.005.

Gaulin, S.J., R.W. FitzGerald, and M.S. Wartell. 1990. Sex differences in spatial ability and activity in two vole species (Microtus ochrogaster and M. pennsylvanicus). Journal of Comparative Psychology 104 (1): 88. 
Gay, V., D.L. Hicks, E. Santacreu-Vasut, and A. Shoham. 2018. Decomposing culture: An analysis of gender, language, and labor supply in the household. Review of Economics of the Household 16 (4): 879-909. https://doi.org/10.1007/s11150-017-9369-x.

Geary, D.C. 1995. Sexual selection and sex differences in spatial cognition. Learning and Individual Differences 7 (4): 289-301.

Geary, D.C. 2010. Male, female: The evolution of human sex differences, 2nd ed. American Psychological Association. https://doi.org/10.1037/12072-000.

Gilbert, D.T., and P.S. Malone. 1995. The correspondence bias. Psychological Bulletin 117: 21-38.

Gislen, A., M. Dacke, R.H.H. Kroger, M. Abrahamsson, D.-E. Nilsson, and E.J. Warrant. 2003. Superior underwater vision in a human population of sea gypsies. Current Biology 13 (10): 833-836.

Giuliano, P. 2018. Gender: A historical perspective. In The Oxford handbook of women and the economy, ed. S.L. Averett, L.M. Argys, and S.D. Hoffman, 644-672. Oxford University Press. https://doi.org/10.1093/oxfordhb/9780190628963.013.29.

Giuliano, P., \& Nunn, N. (forthcoming). Understanding cultural persistence and change. Review of Economics \& Statistics. doi: https://doi.org/10.1007/BF01091620.

Gneezy, U., K.L. Leonard, and J.A. List. 2009. Gender differences in competition: Evidence from a matrilineal and a patriarchal society. Econometrica 77 (5): 1637-1664. https://doi.org/10.3982/ECTA6 690.

Goldman, A., and C. O'Connor. 2019. Social epistemology. In The Stanford encyclopedia of philosophy, ed. E. Zalta (p. https://plato.stanford.edu/archives/fall2019/entries/epistemology-social/).

Goldstein, J., J. Davidoff, and D. Roberson. 2009. Knowing color terms enhances recognition: Further evidence from English and Himba. Journal of Experimental Child Psychology 102 (2): 219-238.

Gómez-Robles, A., W.D. Hopkins, S.J. Schapiro, and C.C. Sherwood. 2015. Relaxed genetic control of cortical organization in human brains compared with chimpanzees. Proceedings of the National Academy of Sciences 112 (48): 14799-14804. https://doi.org/10.1073/pnas.1512646112.

Gong, B., and C.L. Yang. 2012. Gender differences in risk attitudes: Field experiments on the matrilineal Mosuo and the patriarchal Yi. Journal of Economic Behavior and Organization 83 (1): 59-65. https://doi.org/10.1016/j.jebo.2011.06.010.

Gotti, G., S.G. Roberts, M. Fasan, and C.B. Robertson. 2021. Language in economics and accounting research: The role of linguistic history. The International Journal of Accounting 56 (03): 2150015.

Gurven, M.D., and D.E. Lieberman. 2020. WEIRD bodies: Mismatch, medicine and missing diversity. Evolution and Human Behavior 41 (5): 330-340. https://doi.org/10.1016/j.evolhumbehav.2020.04. 001.

Gurven, M., H. Kaplan, J. Winking, D. Eid Rodriguez, S. Vasunilashorn, J.K. Kim, C. Finch, and E. Crimmins. 2009. Inflammation and infection do not promote arterial aging and cardiovascular disease risk factors among lean horticulturalists. PLoS One 4 (8): e6590. https://doi.org/10.1371/journ al.pone. 0006590 .

Gurven, M.D., B.C. Trumble, J. Stieglitz, A.D. Blackwell, D.E. Michalik, C.E. Finch, and H.S. Kaplan. 2016. Cardiovascular disease and type 2 diabetes in evolutionary perspective: A critical role for helminths? Evolution, Medicine and Public Health 2016 (1): 338-357. https://doi.org/10.1093/ emph/eow028.

Gurven, M., T.S. Kraft, S. Alami, J.C. Adrian, E.C. Linares, D. Cummings, D.E. Rodriguez, P.L. Hooper, A.V. Jaeggi, R.Q. Gutierrez, I.M. Suarez, E. Seabright, H. Kaplan, J. Stieglitz, and B. Trumble. 2020. Rapidly declining body temperature in a tropical human population. Science Advances 6 (44): eabc6599. https://doi.org/10.1126/sciadv.abc6599.

Hamilton, V.L., and J. Sanders. 1992. Everyday justice: Responsibility and the individual in Japan and the United States. Yale University Press.

Hamlin, J.K. 2013a. Failed attempts to help and harm: Intention versus outcome in preverbal infants' social evaluations. Cognition 128 (3): 451-474.

Hamlin, J.K. 2013b. Moral judgment and action in preverbal infants and toddlers: Evidence for an innate moral Core. Current Directions in Psychological Science 22 (3): 186-193.

Hamlin, J.K., E.V. Hallinan, and A.L. Woodward. 2008. Do as I do: 7-month-old infants selectively reproduce others' goals. Developmental Science 11 (4): 487-494.

Hamlin, J.K., G.E. Newman, and K. Wynn. 2009. Eight-month-old infants infer unfulfilled goals, despite ambiguous physical evidence. Infancy 14 (5): 579-590.

Han, S.H., G. Northoff, K. Vogeley, B.E. Wexler, S. Kitayama, and M.E.W. Varnum. 2013. A cultural neuroscience approach to the biosocial nature of the human brain. Annual Review of Psychology, Vol 64 (64): 335-359. 
Hansen, H. (2015). Fallacies.

Harris, P.L., and K.H.H. Corriveau. 2011. Young children's selective trust in informants. Philosophical Transactions of the Royal Society B: Biological Sciences 366 (1567): 1179-1187.

Hart, R. 1979. Children's experience of place. Irvington.

Hart, R.A., and G.T. Moore. 1973. The development of spatial cognition: A review. AldineTransaction.

Haun, D.B.M., C.J. Rapold, J. Call, G. Janzen, and S.C. Levinson. 2006. Cognitive cladistics and cultural override in hominid spatial cognition. Proceedings of the National Academy of Sciences of the United States of America 103 (46): 17568-17573.

Hay, Jennifer, and L. Bauer. 2007. Phoneme inventory size and population size. Language 83 (2): $388-$ 400. https://doi.org/10.1353/lan.2007.0071.

Hegarty, M., and D. Waller. 2005. Individual differences in spatial abilities. The Cambridge Handbook of Visuospatial Thinking: 121-169.

Heikinheimo, K., M. Nystrom, T. Heikinheimo, P. Pirttiniemi, and S. Pirinen. 2012. Dental arch width, overbite, and overjet in a Finnish population with normal occlusion between the ages of 7 and 32 years. The European Journal of Orthodontics 34 (4): 418-426.

Heine, S.J. 2012. Cultural psychology. 2nd ed. W.W. Norton.

Heine, S.J. 2016. Cultural psychology. 3rd ed. W. W. Norton \& Company, Inc..

Henderson, D. 2020. Are epistemic norms fundamentally social norms? Episteme. https://doi.org/10. 1017/epi.2019.49.

Henrich, J. 2004. Demography and cultural evolution: How adaptive cultural processes can produce maladaptive losses-The Tasmanian case. American Antiquity 69 (02): 197-214. https://doi.org/10. 2307/4128416.

Henrich, J. 2008. A cultural species. In Explaining culture scientifically, ed. M. Brown, 184-210. University of Washington Press.

Henrich, J. 2009. The evolution of innovation-enhancing institutions. In Innovation in cultural systems: Contributions in evolutionary anthropology, ed. S.J. Shennan and M.J. O'Brien, 99-120. MIT.

Henrich, J. 2016. The secret of our success: How culture is driving human evolution, domesticating our species, and making us smarter. Princeton University Press.

Henrich, J. 2020. The WEIRDest people in the world: How the west became psychologically peculiar and particularly prosperous. Farrar, Straus and Giroux.

Henrich, J., and R. Boyd. 2008. Division of labor, economic specialization, and the evolution of social stratification. Current Anthropology 49 (4): 715-724. https://doi.org/10.1086/587889.

Henrich, J., and F.J. Gil-White. 2001. The evolution of prestige: Freely conferred deference as a mechanism for enhancing the benefits of cultural transmission. Evolution and Human Behavior 22 (3): 165-196. https://doi.org/10.1016/S1090-5138(00)00071-4.

Henrich, N., and J. Henrich. 2007. Why humans cooperate: A cultural and evolutionary explanation. Oxford University Press.

Henrich, J., and R. McElreath. 2002. Are peasants risk-averse decision makers? Current Anthropology 43 (1): 172-181.

Henrich, J., S.J. Heine, and A. Norenzayan. 2010. The weirdest people in the world? Behavioral and Brain Sciences 33 (2-3): 61-83.

Henrich, J., R. Boyd, and P.J. Richerson. 2012. The puzzle of monogamous marriage. Philosophical Transactions of the Royal Society B: Biological Sciences 367 (1589): 657-669. https://doi.org/10. 1098/rstb.2011.0290.

Henrich, J., M. Chudek, and R. Boyd. 2015. The big man mechanism: How prestige fosters cooperation and creates prosocial leaders. Philosophical Transactions of the Royal Society B: Biological Sciences 370 (1683). https://doi.org/10.1098/rstb.2015.0013.

Herculano-Houzel, S. 2019. Life history changes accompany increased numbers of cortical neurons: A new framework for understanding human brain evolution. In Progress in Brain Research (Vol. 250, pp. 179-216). Elsevier. https://doi.org/10.1016/bs.pbr.2019.06.001.

Heyes, C. 2016. Who knows? Metacognitive social learning strategies. Trends in Cognitive Sciences, $x x$ : 1-10. https://doi.org/10.1016/j.tics.2015.12.007.

Hoffman, M., U. Gneezy, and J.A. List. 2011. Nurture affects gender differences in spatial abilities. Proceedings of the National Academy of Sciences 108 (36): 14786-14788.

Hollan, D. 1989. The personal use of dream beliefs in the Toraja highlands. Ethos 17 (2): 166-186.

Hong, Z. 2021. Dream interpretation from a cognitive and cultural evolutionary perspective: The case of oneiromancy in traditional China. PsyArXiv. https://doi.org/10.31234/osf.io/kfzxs. 
Hong, Z., and J. Henrich. 2021. The cultural evolution of epistemic Practices: The Case of Divination. Human Nature. https://doi.org/10.1007/s12110-021-09408-6.

Hong, Z., and Henrich, Joseph. (forthcoming). The cultural evolution of epistemic practices: The case of divination. Human Nature.

Hooven, C. 2021. T: The story of testosterone, the hormone that dominates and divides us. Henry Holt and Company https://books.google.com/books?id=xnb7DwAAQBAJ.

Howe, C.Q., and D. Purves. 2005. The Muller-Lyer illusion explained by the statistics of image-source relationships. Proceedings of the National Academy of Sciences 102 (4): 1234-1239. https://doi. org/10.1073/pnas.0409314102.

Hughes, J.D. 2000. Dream interpretation in ancient civilizations. Dreaming. https://doi.org/10.1023/A: 1009447606158.

Jahoda, G. 1966. Geometric illusions and environment: At study in Ghana. British Journal of Psychology 57: 193-199.

Jang, H., C. Boesch, R. Mundry, V. Kandza, and K.R. Janmaat. 2019. Sun, age and test location affect spatial orientation in human foragers in rainforests. Proceedings of the Royal Society B 286 (1907): 20190934.

Ji, L.-J., K. McGeorge, Y. Li, A. Lee, and Z. Zhang. 2015. Culture and gambling fallacies. SpringerPlus 4 (1): 510. https://doi.org/10.1186/s40064-015-1290-2.

Jones, C.M., V.A. Braithwaite, and S.D. Healy. 2003. The evolution of sex differences in spatial ability. Behavioral Neuroscience 3 (403-411).

Kahan, D., A.R. Landrum, K. Carpenter, L. Helft, and K.H. Jamieson. 2017. Science curiosity and political information processing. Political Psychology 38: 179-199.

Kahneman, D. 2011. Thinking, fast and slow (16846205; 1st ed.). Farrar, Straus and Giroux.

Kaifu, Y., K. Kasai, G.C. Townsend, and L.C. Richards. 2003. Tooth wear and the "design" of the human dentition: A perspective from evolutionary medicine. American Journal of Physical Anthropology 122 (S37): 47-61.

Kauppinen, A. 2018. Epistemic norms and epistemic accountability. Philosopher's Imprint 18 (8): 1-16.

Kay, P., and T. Regier. 2003. Resolving the question of color naming universals. Proceedings of the National Academy of Sciences of the United States of America 100 (15): 9085-9089.

Kay, P., and T. Regier. 2006. Language, thought and color: Recent developments. Trends in Cognitive Sciences 10 (2): 51-54.

Kitayama, S., K. Yanagisawa, A. Ito, R. Ueda, Y. Uchida, and N. Abe. 2017. Reduced orbitofrontal cortical volume is associated with interdependent self-construal. Proceedings of the National Academy of Sciences 114 (30): 7969-7974. https://doi.org/10.1073/pnas.1704831114.

Kitayama, S., Varnum, M. E., \& Salvador, C. E. (2019). Cultural neuroscience.

Kleinfeld, J. 1971. Visual memory in village Eskimo and urban Caucasian children. ARCTIC 24 (2): 132-138. https://doi.org/10.14430/arctic3123.

Kling, A. 2016. Cultural intelligence. National Affairs 27: 150-163.

Knoblock, J. 1988. Xunzi: A translation and study of the complete works (Vol. 1). Stanford University Press.

Koenig, M.A., and M.A. Sabbagh. 2013. Selective social learning: New perspectives on learning from others. Developmental Psychology 49 (3): 399-403.

Kracke, W. 1992. Cultural aspects of dreaming. In Encyclopedia of Dreams. Internationale Institute for Dream Research.

Kuntoro, I.A., L. Saraswati, C. Peterson, and V. Slaughter. 2013. Micro-cultural influences on theory of mind development: A comparative study of middle-class and pemulung children in Jakarta, Indonesia. International Journal of Behavioral Development 37 (3): 266-273. https://doi.org/10.1177/ 0165025413478258.

Laland, K.N. 2004. Social learning strategies. Learning \& Behavior 32 (1): 4-14.

Laland, K.N. 2017. Darwin's unfinished symphony: How culture made the human mind. Princeton University Press. https://doi.org/10.1515/9781400884872.

Levinson, S.C. 2003. Space in language and cognition. Cambridge University Press.

Levy, N., and M. Alfano. 2020. Knowledge from vice: Deeply social epistemology. Mind 129 (515): 887915. https://doi.org/10.1093/mind/fzz017.

Lew-Levy, S., S.M. Kissler, A.H. Boyette, A.N. Crittenden, I.A. Mabulla, and B.S. Hewlett. 2020. Who teaches children to forage? Exploring the primacy of child-to-child teaching among Hadza and BaYaka Hunter-Gatherers of Tanzania and Congo. Evolution and Human Behavior 41 (1): 12-22. https://doi.org/10.1016/j.evolhumbehav.2019.07.003. 
Li, Y.J., K.A. Johnson, A.B. Cohen, M.J. Williams, E.D. Knowles, and Z. Chen. 2012. Fundamental(ist) attribution error: Protestants are dispositionally focused. Journal of Personality and Social Psychology 102 (2): 281-290. https://doi.org/10.1037/a0026294.

Lieberman, D.E. 2011. The evolution of the human head. Harvard University Press https://books.google. com/books?id=KvIDVlSExS8C.

Lieberman, D.E. 2012. What we can learn about running from barefoot running: An evolutionary medical perspective. Exercise and Sport Sciences Reviews 40 (2): 63-72. https://doi.org/10.1097/JES. 0b013e31824ab210.

Lieberman, D. 2013. The story of the human body: Evolution, health, and disease. Random House LLC. Lincoln, J.S. 2003. The dream in native american and other primitive cultures. Courier Corporation.

Lindsey, D.T., A.M. Brown, D.H. Brainard, and C.L. Apicella. 2015. Hunter-gatherer color naming provides new insight into the evolution of color terms. Current Biology 25 (18): 2441-2446. https:// doi.org/10.1016/j.cub.2015.08.006.

Linn, M.C., and A.C. Petersen. 1985. Emergence and characterization of sex differences in spatial ability: A meta-analysis. Child Development: 1479-1498.

Littlejohn, C., \& Turri, J. (Eds.). (2014). Epistemic norms. Oxford Uniaversity Press.

Locke, J. (1690). An essay concerning human understanding.

Lucy, J.A. 1996. The scope of linguistic relativity: An analysis and review of empirical research.

Luhrmann, T.M., R. Astuti, J. Robbins, J. Cassaniti, J. Marrow, J. Lucy, K. Geurts, J. Throop, A. Vilaça, R. Stasch, B. Rogoff, L. Butler, E. Markman, D. Rutherford, S. Gaskins, G. Jones, M. Karnes, D. Gentner, A. Tran, et al. 2011. Toward an anthropological theory of mind. Suomen Antropologi: Journal of the Finnish Anthropological Society 4: 5-69. https://doi.org/10.1007/ s13398-014-0173-7.2.

Luhrmann, T.M., K. Weisman, F. Aulino, J.D. Brahinsky, J.C. Dulin, V.A. Dzokoto, C.H. Legare, M. Lifshitz, E. Ng, N. Ross-Zehnder, and R.E. Smith. 2021. Sensing the presence of gods and spirits across cultures and faiths. Proceedings of the National Academy of Sciences 118 (5): e2016649118. https://doi.org/10.1073/pnas.2016649118.

Lupyan, G., and R. Dale. 2010. Language structure is partly determined by social structure. PLoS One 5 (1): e8559.

Luria, A.R. 1976. Cognitive development: Its cultural and social foundations. Harvard University Press.

Maddux, W.W., H. Yang, C. Falk, H. Adam, W. Adair, Y. Endo, Z. Carmon, and S.J. Heine. 2010. For whom is parting with possessions more painful? Cultural differences in the endowment effect. Psychological Science 21 (12): 1910-1917. https://doi.org/10.1177/0956797610388818.

Majid, A., and N. Burenhult. 2014. Odors are expressible in language, as long as you speak the right language. Cognition 130 (2): 266-270. https://doi.org/10.1016/j.cognition.2013.11.004.

Majid, A., and N. Kruspe. 2018. Hunter-gatherer olfaction is special. Current Biology: 1-5. https://doi. org/10.1016/j.cub.2017.12.014.

Matthews, M.H. 1987. Gender, home range and environmental cognition. Transactions of the Institute of British Geographers, NS12: 43-56. https://doi.org/10.2307/622576.

McCauley, R., and J. Henrich. 2006. Susceptibility to the Muller-Lyer illusion, theory-neutral observation, and the diachronic penetrability of the visual input system. Philosophical Psychology 19 (1): $1-23$.

McElreath, R. 2003. Reputation and the evolution of conflict. Journal of Theoretical Biology 220: 345-357.

McElreath, R., R. Boyd, and P.J. Richerson. 2003. Shared norms and the evolution of ethnic markers. Current Anthropology 44 (1): 122-129.

McNamara, R.A., A.K. Willard, A. Norenzayan, and J. Henrich. 2019. Weighing outcome vs. intent across societies: How cultural models of mind shape moral reasoning. Cognition 182: 95-108.

McNamara, R.A., R. Senanayake, A.K. Willard, and J. Henrich. 2021. God's mind on morality. Evolutionary Human Sciences 3: e6. https://doi.org/10.1017/ehs.2021.1.

McWhorter, J.H. 2008. Our magnificent bastard tongue: The untold history of English. Gotham Books https://books.google.com/books?id=J7rEk4BW0_oC.

Mesoudi, A., L. Chang, K. Murray, and H.J. Lu. 2014. Higher frequency of social learning in China than in the west shows cultural variation in the dynamics of cultural evolution. Proceedings of the Royal Society B-Biological Sciences 282 (1798).

Miller, J.G. 1984. Culture and development of everyday social explanation. Journal of Personality and Social Psychology 46 (5): 961-978. https://doi.org/10.1037/0022-3514.46.5.961. 
Miller, D.J., T. Duka, C.D. Stimpson, S.J. Schapiro, W.B. Baze, M.J. McArthur, A.J. Fobbs, A.M.M. Sousa, N. Sestan, D.E. Wildman, L. Lipovich, C.W. Kuzawa, P.R. Hof, and C.C. Sherwood. 2012. Prolonged myelination in human neocortical evolution. Proceedings of the National Academy of Sciences of the United States of America 109 (41): 16480-16485.

Milton, K. (1988). Foraging behaviour and the evolution of primate intelligence.

Miner, E.J., M. Gurven, H. Kaplan, and S.J.C. Gaulin. 2014. Sex difference in travel is concentrated in adolescence and tracks reproductive interests. Proceedings of the Royal Society B: Biological Sciences 281 (1796): 20141476-20141476. https://doi.org/10.1098/rspb.2014.1476.

Morgan, T.J.H., and K. Laland. 2012. The biological bases of conformity. Frontiers in Neuroscience 6 (87): $1-7$.

Muthukrishna, M., and J. Henrich. 2016. Innovation in the collective brain. Philosophical Transactions of the Royal Society B: Biological Sciences 371 (1690): 1-14.

Muthukrishna, M., T.J.H. Morgan, and J. Henrich. 2016. The when and who of social learning and conformist transmission. Evolution and Human Behavior 37 (1): 10-20.

Muthukrishna, M., M. Doebeli, M. Chudek, and J. Henrich. 2018a. The cultural brain hypothesis: How culture drives brain expansion, sociality, and life history. PLoS Computational Biology 14 (11): e1006504. https://doi.org/10.1371/journal.pcbi.1006504.

Muthukrishna, M., J. Henrich, W. Toyokawa, T. Hamamura, T. Kameda, and S.J. Heine. 2018b. Overconfidence is universal? Elicitation of genuine overconfidence (EGO) procedure reveals systematic differences across domain, task knowledge, and incentives in four populations. PLoS One 13 (8): e0202288. https://doi.org/10.1371/journal.pone.0202288.

Muthukrishna, M., J. Henrich, and E. Slingerland. 2021. Psychology as a historical science. Annual Review of Psychology 72 (1): 717-749. https://doi.org/10.1146/annurev-psych-082820-111436.

National Science Board. 2018. Science and engineering indicators 2018 (NSB-2018-1). National Science Foundation. https://www.nsf.gov/statistics/indicators/

Nguyen, C.T. 2020. ECHO CHAMBERS AND EPISTEMIC BUBBLES. Episteme 17 (2): 141-161. https://doi.org/10.1017/epi.2018.32.

Nisbett, R.E. 2003. The Geography of Thought: How Asians and Westerners Think Differently...and Why. The Free Press.

Nisbett, R., K. Peng, I. Choi, and A. Norenzayan. 2001. Culture and systems of thought: Holistic vs. analytic cognition. Psychological Review 108 (2): 291-310.

Norenzayan, A., E.E. Smith, B.J. Kim, and R.E. Nisbett. 2002. Cultural preferences for formal versus intuitive reasoning. Cognitive Science 26 (5): 653-684.

Park, J., Y. Uchida, and S. Kitayama. 2016. Cultural variation in implicit independence: An extension of Kitayama et al. (). International Journal of Psychology 51 (4): 269-278.

Peng, K., and R.E. Nisbett. 1999. Culture, dialectics, and reasoning about contradiction. American Psychologist 54 (9): 741-754.

Peters, U. 2020. What is the function of confirmation Bias? Erkenntnis: 1-26.

Pope, S.M., J. Fagot, A. Meguerditchian, D.A. Washburn, and W.D. Hopkins. 2018. Enhanced Cognitive Flexibility in the Seminomadic Himba. Journal of Cross-Cultural Psychology: 002202211880658. https://doi.org/10.1177/0022022118806581.

Powell, R.A., and M.S. Mitchell. 2012. What is a home range? Journal of Mammalogy 93 (4): 948-958.

Protsiv, M., C. Ley, J. Lankester, T. Hastie, and J. Parsonnet. 2020. Decreasing human body temperature in the United States since the industrial revolution. ELife 9: e49555. https://doi.org/10.7554/eLife. 49555.

Proulx, M.J., O.S. Todorov, A. Taylor Aiken, and A.A. de Sousa. 2016. Where am I? Who am I? The relation between spatial cognition, social cognition and individual differences in the built environment. Frontiers in Psychology 7: 64.

Raymond, L., and D. Kelly. forthcoming. Norm-based governance for a new era: Collective action in the face of hyper-politicization. Perspectives on Politics.

Rendell, L., L. Fogarty, W.J.E. Hoppitt, T.J.H. Morgan, M.M. Webster, and K.N. Laland. 2011. Cognitive culture: Theoretical and empirical insights into social learning strategies. Trends in Cognitive Sciences 15 (2): 68-76.

Rini, R. 2017. Fake news and partisan epistemology. Kennedy Institute of Ethics Journal 27 (2): E-43.

Rivers, W.H.R. 1901. Introduction and vision. In Reports of the Cambridge anthropological expedition to the Torres Straits: Vol. II, ed. A.C. Haddon. The University Press.

Robbins, J., and A. Rumsey. 2008. Introduction: Cultural and linguistic anthropology and the opacity of other minds. Anthropological Quarterly 81 (2): 407-420. 
Robbins, E., J. Shepard, and P. Rochat. 2017. Variations in judgments of intentional action and moral evaluation across eight cultures. Cognition 164: 22-30. https://doi.org/10.1016/j.cognition.2017. 02.012 .

Roberts, S.G., J. Winters, and K. Chen. 2015. Future tense and economic decisions: Controlling for cultural evolution. PLoS One 10 (7): e0132145. https://doi.org/10.1371/journal.pone.0132145.

Rogoff, B. 1981. Schooling and the development of cognitive skills. Handbook of Cross-Cultural Psychology 4: 233-294.

Rosenthal, T.L., and B.J. Zimmerman. 1978. Social learning and cognition. Academic Press.

Rudinow, J. 2008. Invitation to critical thinking. Thomson Wadsworth.

Rudy-Hiller, F. 2019. Rudy-Hiller, Fernando, "The Epistemic Condition for Moral Responsibility",. In The Stanford Encyclopedia of Philosophy (Winter 2019 Edition). https://plato.stanford.edu/entries/ moral-responsibility/

Rushton, J.P. 1975. Generosity in children: Immediate and long term effects of modeling, preaching, and moral judgement. Journal of Personality and Social Psychology 31: 459-466.

Sachdeva, S., P. Singh, and D. Medin. 2011. Culture and the quest for universal principles in moral reasoning. International Journal of Psychology : Journal International de Psychologie 46 (3): 161176. https://doi.org/10.1080/00207594.2011.568486.

Sacks, O. 2012. The island of the colorblind. Knopf Doubleday Publishing Group https://books.google. com/books?id=9p_RY4ujCTQC.

Salali, G.D., M. Juda, and J. Henrich. 2015. Transmission and development of costly punishment in children. Evolution and Human Behavior 36 (2): 86-94 https://doi.org/10.1016/j.evolhumbehav.2014. 09.004.

Schaffner, B.F., and S. Luks. 2018. Misinformation or expressive responding? What an inauguration crowd can tell us about the source of political misinformation in surveys. Public Opinion Quarterly 82: $135-147$.

Schieffelin, B. 1990. The give and take of everyday life: Language socialization of Kaluli children. Cambridge University Press.

Schieffelin, B. 2008. Speaking only your own mind: Reflections on talk, gossip and intentionality in Bosavi (PNG). Anthropological Quarterly 81 (2): 431-441.

Schulz, J.F., D. Bahrami-rad, J.P. Beauchamp, and J. Henrich. 2019. The church, intensive kinship, and global psychological variation. Science 366 (707). https://doi.org/10.1126/science.aau5141.

Scribner, S. 1975. Recall of classical syllogisms: A cross-cultural investigation of error on logical problems. In Reasoning: Representation and process, 154-173. Lawrence Erlbaum Associates.

Scribner, S., and M. Cole. 1973. Cognitive consequences of formal and informal education: New accommodations are needed between school-based learning and learning experiences of everyday life. Science 182 (4112): 553-559. https://doi.org/10.1126/science.182.4112.553.

Segall, M., D.T. Campbell, and M.J. Herskovits. 1963. Cultural differences in the perception of geometric illusions. Science 139 (3556): 769-771.

Segall, M., D. Campbell, and M.J. Herskovits. 1966. The influence of culture on visual perception. The Bobbs-Merrill Company.

Selcuk, B., K.A. Brink, M. Ekerim, and H.M. Wellman. 2018. Sequence of theory-of-mind acquisition in Turkish children from diverse social backgrounds. Infant and Child Development 27 (4): 1-14. https://doi.org/10.1002/icd.2098.

Sharp, D., M. Cole, C. Lave, H.P. Ginsburg, A.L. Brown, and L.A. French. 1979. Education and cognitive development: The evidence from experimental research. Monographs of the Society for Research in Child Development 44 (1/2): 1. https://doi.org/10.2307/3181586.

Sherwood, C.C., and A. Gómez-Robles. 2017. Brain plasticity and human evolution. Annual Review of Anthropology 46 (1): 399-419. https://doi.org/10.1146/annurev-anthro-102215-100009.

Sherwood, C.C., A.L. Bauernfeind, S. Bianchi, M.A. Raghanti, and P.R. Hof. 2012. Human brain evolution writ large and small. In Progress in brain research (1st ed., Vol. 195). Elsevier B.V. https://doi. org/10.1016/B978-0-444-53860-4.00011-8.

Silverman, I., J. Choi, and M. Peters. 2007. The hunter-gatherer theory of sex differences in spatial abilities: Data from 40 countries. Archives of Sexual Behavior 36 (2): 261-268.

Singh, M. 2018a. The cultural evolution of shamanism. Behavioral and Brain Sciences 41. https://doi. org/10.1017/S0140525X17001893.

Singh, M. 2018b. Magic, explanations, and evil: On the origins and design of witches and sorcerers [Preprint]. SocArXiv. https://doi.org/10.31235/osf.io/pbwc7. 
Smith, K.M., and C.L. Apicella. 2020. Partner choice in human evolution: The role of cooperation, foraging ability, and culture in Hadza campmate preferences. Evolution and Human Behavior 41 (5): 354-366. https://doi.org/10.1016/j.evolhumbehav.2020.07.009.

Sorokowska, A., P. Sorokowski, T. Hummel, and T. Huanca. 2013. Olfaction and environment: Tsimane' of Bolivian rainforest have lower threshold of odor detection than industrialized German people. PLoS One 8 (7): e69203. https://doi.org/10.1371/journal.pone.0069203.

Spina, R.R., L.-J. Ji, M. Ross, Y. Li, and Z. Zhang. 2010a. Why best cannot last: Cultural differences in predicting regression toward the mean: Culture and regression. Asian Journal of Social Psychology 13 (3): 153-162. https://doi.org/10.1111/j.1467-839X.2010.01310.x.

Spina, R.R., L.-J. Ji, Tieyuan Guo, Zhiyong Zhang, Ye Li, and L. Fabrigar. 2010b. Cultural differences in the representativeness heuristic: Expecting a correspondence in magnitude between cause and effect. Personality and Social Psychology Bulletin 36 (5): 583-597. https://doi.org/10.1177/01461 67210368278.

Stahl, T., M.P. Zaal, and L.J. Skitka. 2016. Moralized rationality: Relying on logic and evidence in the formation and evaluation of belief can be seen as a moral issue. PLoS One 11 (11): e0166332.

Stich, S. 2006. Is morality an elegant machine or a kludge? Journal of Cognition and Culture 6 (1-2): 181-189. https://doi.org/10.1163/156853706776931349.

Stich, S., and Masaharu Mizumoto. forthcoming. Manifesto. In Epistemology for the rest of the world. Oxford University Press.

Stieglitz, J., M. Gurven, H. Kaplan, and P.L. Hooper. 2013. Household task delegation among high-fertility forager-horticulturalists of lowland Bolivia. Current anthropology 54 (2): 232-241.

Stokes, D. 2018. Attention and the cognitive penetrability of perception. Australasian Journal of Philosophy 96 (2): 303-318.

Street, S.E., A.F. Navarrete, S.M. Reader, and K.N. Laland. 2017. Coevolution of cultural intelligence, extended life history, sociality, and brain size in primates. Proceedings of the National Academy of Sciences 114 (30): 7908-7914. https://doi.org/10.1073/pnas.1620734114.

Strevens, M. 2020. The knowledge machine: How an unreasonable idea created modern science. Penguin Books Limited https://books.google.com/books?id=zXvNDwAAQBAJ.

Talhelm, T. 2020. Emerging evidence of cultural differences linked to rice versus wheat agriculture. Current Opinion in Psychology 32: 81-88. https://doi.org/10.1016/j.copsyc.2019.06.031.

Talhelm, T., X. Zhang, S. Oishi, C. Shimin, D. Duan, X. Lan, and S. Kitayama. 2014. Large-scale psychological differences within China explained by rice versus wheat agriculture. Science 344: 603-608.

Tarampi, M.R., N. Heydari, and M. Hegarty. 2016. A tale of two types of perspective taking: Sex differences in spatial ability. Psychological Science 27 (11): 1507-1516.

Tedlock, B. 1987. Dreaming: Anthropological and psychological interpretations. CUP Archive.

Thoma, D., and A.E. Tytus. 2018. How cross-linguistic differences in the Grammaticalization of future time reference influence intertemporal choices. Cognitive Science 42 (3): 974-1000. https://doi. org/10.1111/cogs. 12525 .

Tibana, R.H.W., L.M. Palagi, and J.A.M. Miguel. 2004. Changes in dental arch measurements of Young adults with Normal occlusion-A longitudinal study. Angle Orthodontist 74 (5): 6.

Tomasello, M. 2020. The ontogenetic foundations of epistemic norms. Episteme 17: 301-315.

Trudgill, P. 2011. Sociolinguistic typology: Social determinants of linguistic complexity. Oxford University Press.

Trumble, B.C., S.J.C. Gaulin, M.D. Dunbar, H. Kaplan, and M. Gurven. 2015. No sex or age difference in dead-reckoning ability among Tsimane forager-horticulturalists. Human Nature.

Tuttle, R., D. Webb, E. Weidl, and M. Baksh. 1990. Further Progress on the Laetoli trails. Journal of Archaeological Science 17 (3): 347-362.

Tuttle, R., D. Webb, and M. Baksh. 1991. Laetoli toes and Australopithecus afarensis. Human Evolution 6 (3): 193-200.

Vander Heyden, K.M., M. Huizinga, M. Raijmakers, and J. Jolles. 2017. Children's representations of another person's spatial perspective: Different strategies for different viewpoints? Journal of Experimental Child Psychology 153: 57-73.

Vashro, L., and E. Cashdan. 2015. Spatial cognition, mobility, and reproductive success in northwestern Namibia. Evolution and Human Behavior 36 (2): 123-129. https://doi.org/10.1016/j.evolhumbeh av.2014.09.009.

Vashro, L., L. Padilla, and E. Cashdan. 2016. Sex differences in mobility and spatial cognition: A test of the fertility and parental care hypothesis in northwestern Namibia. Human Nature 27 (1): 16-34. https://doi.org/10.1007/s12110-015-9247-2. 
Vasilyeva, M., and S.F. Lourenco. 2012. Development of spatial cognition. Wiley Interdisciplinary Reviews: Cognitive Science 3 (3): 349-362.

Vieider, F.M., M. Lefebvre, R. Bouchouicha, T. Chmura, R. Hakimov, M. Krawczyk, and P. Martinsson. 2015. Common components of risk and uncertainty attitudes across contexts and domains: Evidence from 30 countries. Journal of the European Economic Association 13 (3): 421-452. https:// doi.org/10.1111/jeea.12102.

Vinden, P.G. 1999. Children's understanding of mind and emotion: A multi-culture study. In Cognition and emotion (Vol. 13, issue 1, p. 48). https://doi.org/10.1080/026999399379357.

Vinden, P.G. 2002. Understanding minds and evidence for belief: A study of Mofu children in Cameroon. International Journal of Behavioral Development 26 (5): 445-452. https://doi.org/10.1080/01650 250143000391.

Voyer, D., S. Voyer, and M.P. Bryden. 1995. Magnitude of sex differences in spatial abilities: A metaanalysis and consideration of critical variables. Psychological Bulletin 117: 250.

Walton, D., and M. Koszowy. 2014. Two kinds of Arguments from Authority in the ad Verecundiam Fallacy. Scholarship at UWindsor.

Wang, R.F., and E.S. Spelke. 2002. Human spatial representation: Insights from animals. Trends in Cognitive Sciences 6 (9): 376-382.

Wang, Z., R.T. Devine, K.K. Wong, and C. Hughes. 2016. Theory of mind and executive function during middle childhood across cultures. Journal of Experimental Child Psychology 149: 6-22. https:// doi.org/10.1016/j.jecp.2015.09.028.

Wellman, H.M., F. Fang, D. Liu, L. Zhu, and G. Liu. 2006. Scaling of theory-of-mind understandings in Chinese children. Psychological Science 17 (12): 1075-1081.

Whiting, B.B., and C.P. Edwards. 1992. Children of different worlds: The formation of social behavior. Harvard University Press.

Wierzbicka, A. 2013. Imprisoned in English: The hazards of English as a default language. Oxford University Press https://books.google.com/books?id=Zr48BAAAQBAJ.

Willard, A.K., and R.A. McNamara. 2019. The minds of God (s) and humans: Differences in mind perception in Fiji and North America. Cognitive Science 43 (1): e12703.

Wootton, D. 2016. Invention of science: A new history of the scientific revolution. https://www.penguin. co.uk/books/132/132992/the-invention-of-science/9780141040837.html

Wundt, W. 1916. Elements of folk psychology: Outlines of a psychological history of the development of mankind. (E. L. Schaub, Trans.). George Allen \& Unwin. http://content.apa.org/books/13042-000

Yates, J. F., Lee, J.-W., \& Bush, J. G. G. (1997). General knowledge overconfidence: Cross-national variations, response style, and "reality." Organizational Behavior and Human Decision Processes, 70(2), 87-94.

Yates, J.F., J. Lee, H. Shinotsuka, A. Patalano, and W. Sieck. 1998. Cross-cultural variations in probability judgment accuracy: Beyond general knowledge overconfidence? Organizational Behavior and Human Decision Processes 74 (2): 89-117.

Yegian, A.K., S.B. Heymsfield, Daniel E. Heymsfield, and D.E. Lieberman. 2021. Historical body temperature records as a population-level 'thermometer' of physical activity in the United States. Current Biology 31 (20): R1375-R1376. https://doi.org/10.1016/j.cub.2021.09.014.

Yi-long, H. 2020. Court divination and Christianity in the K'Ang-Hsi era. East Asian Science, Technology, and Medicine. https://doi.org/10.1163/26669323-01001001.

Young, L., and R. Saxe. 2008. The neural basis of belief encoding and integration in moral judgment. NeuroImage 40: 1912-1920. https://doi.org/10.1016/j.neuroimage.2008.01.057.

Young, L., and R. Saxe. 2009. Innocent intentions: A correlation between forgiveness for accidental harm and neural activity. Neuropsychologia 47: 2065-2072. https://doi.org/10.1016/j.neuropsychologia. 2009.03.020.

Young, L., F. Cushman, M. Hauser, and R. Saxe. 2007. The neural basis of the interaction between theory of mind and moral judgment. Proceedings of the National Academy of Sciences of the United States of America 104 (20): 8235-8240.

Publisher's Note Springer Nature remains neutral with regard to jurisdictional claims in published maps and institutional affiliations. 